\title{
Affiliation and Dominance in Female and Male Dyads: When Discoordination Makes Happy
}

\section{Melisa Stevanovic $^{1}$ (D) Pentti Henttonen ${ }^{1} \cdot$ Mikko Kahri $^{1} \cdot$ Sonja Koski $^{1}$}

Published online: 27 June 2018

(c) The Author(s) 2018

\begin{abstract}
Drawing on sixteen 45-min-long dyadic same-sex conversations between unacquainted females or males, we used the joystick method by Sadler et al. (J Pers Soc Psychol 97:1005-1020. https://doi.org/10.1037/a0016232, 2009) to rate the moment-to-moment levels of affiliation and dominance during the first and last 10 min of these conversations. Besides comparing the behavioral patterns in female and male dyads, we drew on the pre- and post-conversation questionnaires filled by the participants of the rated conversations to study the experiential consequences (valence, arousal, happiness, anxiety) of these patterns. Both genders exhibited the same complementary patterns where affiliation pulls for affiliation and dominance for submissiveness. However, these patterns were experienced differently by females and males. Greater affiliation synchrony increased the levels of happiness and arousal for males, but not for females. In addition, greater dominance coordination predicted a more negative valence change for females than for males. The paper thus points to gender differences in what constitutes a positive interactional experience and suggests a need to revisit social scientific theorizing in this regard.
\end{abstract}

Keywords Conversation · Affiliation · Dominance $\cdot$ Interpersonal theory $\cdot$ Joystickmethod $\cdot$ Gender differences

\section{Introduction}

There is a long tradition of studies pointing to differences in everyday communication patterns between women and men $[12,38]$. Tannen [72] has argued that women's and men's communication patterns are so vastly different that men and women could be seen to belong to different linguistic communities. Women have been found to be more expressive, tentative, polite and relationship-oriented in conversation, while men have been observed to be more assertive, power-hungry, independent,

Melisa Stevanovic

melisa.stevanovic@helsinki.fi

1 University of Helsinki, Helsinki, Finland 
and oriented to tangible outcomes $[4,36,37,42,45,53,58,66,75,85]$. With regard to nonverbal communication, women have been found to smile and laugh more than men [24], to nod in agreement more frequently [28], to be better encoders and decoders of facial expressions [60] and, in general, to be more alert to nonverbal behavior and the specific messages they convey [7, 24, 47].

Despite all the research above, there is not much research on potential differences in how women and men coordinate and synchronize their conversational behaviors and how possible differences in this regard are experienced by women and men. These are the questions addressed in this paper. Drawing on the interpersonal theory [68], we examine a data set of sixteen 45-min-long dyadic same-gender conversations between unacquainted participants. By using the joystick method developed by Sadler et al. [61], we compare the ways in which women and men coordinate and synchronize their affiliative and dominant interpersonal behaviors during a conversation. Furthermore, we consider the experiential consequences of these patterns for both genders.

\section{Interpersonal Theory and the Study of Behavioral Coordination}

To be able to study interactional patterns and their experiential consequences, we need conceptual tools to deal with the wide range of communicative behaviors occurring during conversations. Here, we draw on the interpersonal theory of personality by Sullivan and others $[11,39,68]$. The goal of the theory is "to obtain categories of increasing generality that permit description of behaviors according to their natural relationships" [63, p. 126].

The interpersonal approach is characterized by several leading ideas. The first is the assumption that the most important variation in interpersonal behavior occurs along just two dimensions: dominance versus submissiveness, and friendliness versus hostility $[11,32,33]$. A large body of work links these two dimensions to the two overarching motivational preoccupations that people are assumed to have when dealing with others: the need for agency and the need for communion [3, 83]. Viewing interactional behaviors through these two rather general dimensions has a specific advantage: it allows one to treat also non-identical behaviors as having a comparable relational meaning, inasmuch as they belong to the same major functional class of interactional behavior. For the sake of simplicity, we will henceforth refer to these two dimensions of interpersonal behavior as affiliation and dominance.

The different characterizations of interpersonal behavior, such as shyness or assertiveness, have been argued to form a circular arrangement [22, 32, 39, 81, 82], which is commonly referred to as the interpersonal circumplex. The circle of variables is organized around the axes of affiliation and dominance, which form a twodimensional Cartesian plane (Fig. 1). The circumplex structure implies that those characterizations of behavior that fall close together on the circle are more related than those that fall further apart. Moreover, two characterizations of behavior placed at the opposite sides of the circle are expected to be negatively related.

The interpersonal theory contends that people in dyadic interactions often behave in ways that invoke quite specific behaviors from others [11, 32, 33, 44, 
Fig. 1 Circumplex structure of interpersonal behaviors (adapted from Leary [39]; Wiggins [82]; Kiesler [32])

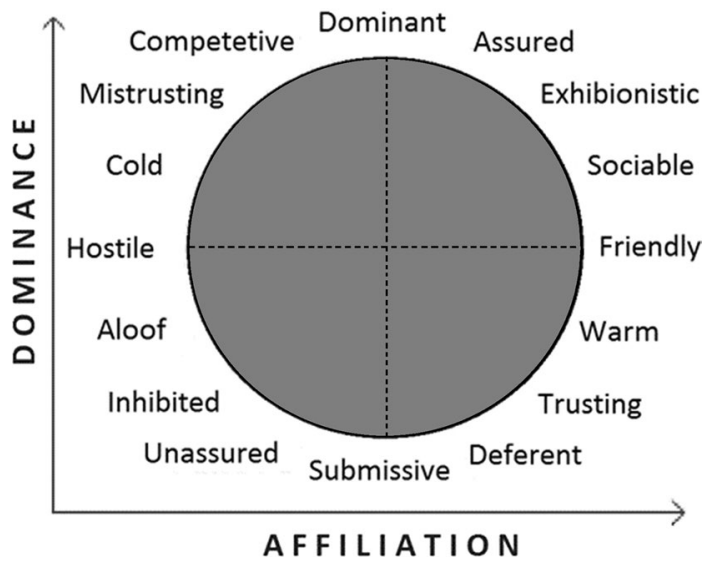

$62,76,82]$. More specifically, with regard to dominance, the expected relation in such covariation has been suggested to be one of oppositeness: greater dominance in one participant tends to invoke greater submissiveness in the co-participant, and vice versa. With regard to affiliation, in contrast, the expected relation has been proposed to be one of sameness: greater affiliation in one participant tends to invoke greater affiliation in the co-participant and, vice versa (see also studies on the notions of emotional contagion [27], affective synchrony [59] and behavioral convergence [20, 43, 51, 52]). These two patterns comprise what interpersonal theorists refer to as complementarity. Complementarity is understood to confirm self-concepts and reduce anxiety, whereas anti-complementarity (oppositeness in affiliation and sameness in dominance) is seen to challenge the participants' views of themselves and increase anxiety [40, p. 474].

Traditionally, the interpersonal theory of personality has been used to characterize the relatively static interpersonal styles of the two individuals in a dyad [23, $64,86]$. The same idea, however, can also be applied to describe the moment-tomoment changes in the participants' behaviors during dyadic interactions. To this aim, Sadler et al. [40, 61] have recently developed and validated a new method. Being based on the assumption that the circumplex structure of interpersonal behaviors is intuitively accessible to raters [82], the method consists of collecting naïve observers' ratings of affiliation and dominance.

In the method, the observer watches an episode of video-recorded social interaction on a computer monitor, focusing his or her attention on one participant at a time. Then, using a computer joystick, the observer assesses the level of affiliation and dominance in the participant's behavior from moment to moment. The various possible positions of the joystick comprise a Cartesian plane with the degree of dominance as the vertical axis and the degree of affiliation as the horizontal axis. A computer software records the coordinates of the joystick position at regular time intervals, thus providing a continuous record of the target participant's interpersonal behaviors during the assessed episode. Later, the observer watches the video again, focusing on the other participant. 
The time-series representing the affiliative and dominant behaviors of each participant within a dyad can be subsequently combined. This allows one to study how the interpersonal behaviors of one participant relate to those of the other participants in the course of the moment-by-moment unfolding of the assessed episode. By using the joystick method, Sadler et al. [61] have, for example, established that the notion of complementarity is not only an overall phenomenon of personality or interpersonal style but that it is subject to constant changes and co-regulation by the participants during the course of interaction.

\section{Gender and Interpersonal Behavior}

The topic of gender is deeply interwoven with the interpersonal approach. In his essay in the field of psychology of religion, Bakan [3] argued that dominance is prototypically masculine and affiliation prototypically feminine. Later studies in the domains of psychology, social psychology and communication have also acknowledged these gender differences but linked their existence more or less to the processes of socialization. Thus, Eagly [18], for example, famously argued that the stereotypic male and female behaviors to arise from the social roles assumed by men and women. All in all, women have been argued to be more emotionally expressive than men $[8,9,24,25]$ and men have been demonstrated to be more dominant than women, for example, regarding the amount of talk [38], the use of directives [49], and the tendency to engage in interruptions [1]. Many of these gender characteristics have been found to be particularly prevalent in mixed-gender dyads. However, there are also authors pointing to differences in men's and women's overall communication styles, which become apparent also when comparing female and male interactions in same-gender dyads [2]. Thus, for example, the form of overlap referred to as "supporting interrupting" [84] has been found to be particularly common in allfemale groups [14].

Empirical research on social interaction in the fields of conversation analysis and discourse analysis has been clear in warning the researchers to consider interpersonal behaviors as direct reflections of participants' internal emotional states. For example, the majority of facial expressions by conversational participants have been found to have discourse functions that cannot be accounted for with reference to underlying emotions [13]. Given the separation between interactional patterns, on one hand, and the participants experiences of these patterns, on the other, previous literature in the domains of psychology, social psychology and sociology points to the possibility that there may be gender differences (also) in this regard. For example, it has been proposed that, in uncomfortable situations, women may be more likely than men to display positive emotions to strive to relieve social tension or to appear cheerful in spite of tension [26, 29, 30, 35, 78]. Smiling in particular has been suggested to be ambiguous as to its "real" emotional meaning, with some authors arguing that smiling reflects false positivity in women but not in men [10].

While we still know relatively little about the extent to which female and male participants' interpersonal behaviors correspond to their experiential states, still less is known about how female and male participants experience their co-participants' 
moment-to-moment affiliative and dominant interpersonal behaviors in relation to analogous behaviors of their own. It is this question that we will address in this study.

\section{Research Questions and Hypotheses}

Our research has been guided by the following research questions:

RQ1 How are the dominant and affiliative interpersonal behaviors in the female and male dyads patterned during the first and last ten minutes of conversation?

RQ2 What are the experiential consequences of the participants' dominant and affiliative interpersonal behaviors in the female and male dyads?

Regarding our first research question (RQ1), we hypothesized that the patterns of dominant and affiliative behavior would be different during the first and last ten minutes of conversation. Given that conversations between unacquainted participants are governed by a range of normative expectations that help the participants to deal with their co-participants' unfamiliarity, we expected the phenomenon of complementarity (sameness in affiliation and oppositeness in dominance) to be stronger during the beginning segments of conversations than during their end segments. However, with reference to the idea of behavioral convergence over time, we also considered the alternative possibility that participants would need some time to adjust to each other's characteristic ways of expressing of affiliation and dominance. Therefore, the alternative expectation was that the patterns of complementarity would be stronger during the end segments of conversation than during their beginning segments. As for possible gender differences, we expected that females would express affiliation more than males and also match each other's affiliative behaviors on a moment-bymoment basis more precisely than males. Further, we anticipated that males would display more dominance than females and also coordinate their dominant behaviors more accurately than females. Indeed, we expected such gender differences to be relatively strong-given the previous findings showing that gender differences are maximized high stress situations, such as conversations between two strangers.

As for our second research question (RQ2), we expected the participants' dominant and affiliative behaviors to have a bearing (1) on the difference between the participants' self-reported feelings before and after the conversation (valence change, arousal change), as well as (2) on the positive and negative emotions experienced during the conversation, as reported after the conversation (happiness, anxiety). On the basis of earlier findings on the effect of co-participant affiliation for the participants' calm emotional state [55], we anticipated that partner-affiliation would lead to an increased level of positive valence and happiness and to a reduced level of arousal and anxiety. Furthermore, drawing on interpersonal theory, according to which complementarity confirms self-concepts, we hypothesized that the maximum levels of happiness and the minimum levels of anxiety would also be driven by sameness in 
affiliation and oppositeness in dominance. As for gender differences in this regard, the existing literature did not allow us to formulate any clear hypotheses.

\section{Method}

\section{Participants and Procedure for Obtaining the Video-Recorded Interaction Material}

The video-recorded interaction material used in the study consist of 16 Finnish faceto-face dyadic conversations in a quasi-natural setting. The participants of the study are 14 females in 7 female dyads and 18 males in 9 male dyads. ${ }^{1}$ The participants did not know each other from before; they had been recruited to the study via email lists.

The participants were instructed to discuss happy events and losses in their lives. Of course, a conversational task such as this may be thought to introduce specific idiosyncratic dynamics into the encounter. It is worth noting, however, that the situations that we simulated in our experiments correspond quite closely to the interactional encounters in different types of self-help settings, where strangers are asked to interact with each other. We thought that a specific conversational task would ease the tension between the participants as they will not need to come of with a conversational agenda of their own. This indeed appeared to be the case, as the participants usually started their conversations by discussing the task instructions, thus immediately establishing a common topic of interest. Furthermore, people are usually well socialized into storytelling practices, while their stories typically involve an affective (e.g., happy or sad) component. We therefore considered our task instruction both easy enough for the participants to create a conversation in which they can become immersed and extensive enough for the participants not to run out of things to talk about during the recording.

During the conversations, the participants were seated in armchairs facing each other perpendicularly. The conversations were videotaped with three cameras: one facing each of the two participants, and the third giving an overall view of the situation. In addition to the video-recording, the participants' psychophysiological activations (e.g., electrodermal activity and heart rate) were recorded for the purposes of another study. The conversations lasted 45-60 min (after $45 \mathrm{~min}$ of discussion, some participants still wanted to continue the conversation for an extra $15 \mathrm{~min}$ ). All participants were informed about the use of the data and signed a consent form.

As material for the study, we used two 10-min segments from each dyadic conversation: one from the beginning of the conversation and the other from the end

\footnotetext{
1 Our set of male dyads had been used in an earlier study as a comparison for another set of male dyads where one participant had Asperger syndrome and another participant was a healthy neurotypical male [67]. Self-evidently, in our current study, we used only the first data set with two healthy neurotypical male participants. Furthermore, the research agenda and analyses are quite different from those in the earlier study.
} 
of it (minutes 35-45, before the above-mentioned question by the experimenter). According to Sadler et al. [61], $10 \mathrm{~min}$ is a sufficient length of time to pick up any stable patterns of interaction. However, we wanted to be able to compare whether there would be differences between the male and female dyads as to how fast the participants adjust to each other's overall levels of dominance and affiliation during the conversation and therefore included the two 10-min segments. Thus, the total amount of 10-min segments rated was 64 .

\section{Pre- and Post-conversation Questionnaires}

To measure the experiential outcomes of the conversations, the participants were asked to fill in a brief questionnaire before and after the conversation. The questionnaires included selected items from the Positive and Negative Affect Schedule (PANAS), which is designed to measure independent dimensions of positive and negative affect $[74,79,80]$. Valence and arousal were measured using SAM (SelfAssessment Manikin) pictorial affect scales, where each participant is asked to assess - on a scale from 1 to 9-how pleasant (valence) and how aroused (arousal) they felt at that particular moment [5]. To reduce the number of dependent variables, factor analytical methods were used to compress the data to a smaller number of latent constructs. Principal component analysis with Varimax rotation (allowing the resultant factors to correlate) was performed on PANAS items (14) and it produced a 4 -factor solution accounting for $72.53 \%$ of the total variance. Cronbach's alpha $(\alpha)$ [17] was calculated to assess the internal reliability of the factors. Factors were interpreted as happiness (PA/Joviality; items = enthusiastic, happy, cheerful, joyful, $\alpha=0.86$ ), anxiety (NA/Fear; items = nervous, relaxed (inverted), calm (inverted), afraid, $\alpha=0.69$ ), sadness (NA/Sadness; items =sad, upset, relaxed (inverted), $\alpha=0.75$ ) and boredom (Fatigue; items =enthusiastic (inverted), tired, sluggish, $\alpha=0.55$ ). Regressed factor scores were calculated for the participants. Also, a compound measure for friendship readiness was calculated using two items ("Would like to spend time with partner" and "Would become friends with partner").

In this study, we will focus on the following experiential outcome measures: (1) the difference between the participants' self-reported feelings before and after the conversation (valence change, arousal change), and (2) the positive and negative emotions experienced during the conversation, as reported after the conversation (happiness, anxiety).

\section{Computer Joystick Apparatus}

We used a computer-joystick apparatus to assess the participants' moment-tomoment dominant and affiliative interpersonal behaviors throughout the course of the above-described interaction segments. The apparatus consisted of a Logitech Extreme 3D Pro-joystick (http://gaming.logitech.com/en-us/product/extre me-3d-pro-joystick; see [40]), which was connected to a Hewlett Packard Windows PC. We wrote the experiments in Matlab with the help of the Psychophysics Toolbox extensions $[6,34,54]$. The software displayed a Cartesian plane of the size of 
approximately $12 \times 12 \mathrm{~cm}$ on the computer screen. The left and right endpoints on the $\mathrm{x}$-axis were labeled as hostile and friendly, respectively, and the top and bottom endpoints on the y-axis as dominant and submissive, respectively. Scale on both axes ranged from 0 to 65,535 such that the midpoint on the Cartesian plane (the rest position of the joystick) was at $(32,767,32,767)$.

The Matlab-operated joystick software program was set to write the joystick position within the Cartesian plane (reflecting the $\mathrm{x}$ and $\mathrm{y}$ coordinates) to a data structure thirty times per second. A dot that moved in accordance with the momentto-moment position of the joystick was shown in the Cartesian plane. Movement along the horizontal axis indexed shifts in affiliation-related interpersonal behaviors, while movement along the vertical axis indexed shifts in dominance-related behaviors. The videotape of the interaction being rated appeared on the same computer screen as the Cartesian plane, so that trained observers could watch the interaction and see their current joystick position simultaneously. The videotaped interaction appeared within a window of the size of $25 \times 30 \mathrm{~cm}$, and the Cartesian plane was always located on the same side of the screen as the participant being rated.

\section{Training Procedure for Observers}

Three independent observers used the joystick apparatus to continuously rate the behaviors for all participants. All three observers were graduate students, who were unaware of the research questions and hypotheses of the study.

Before rating the conversational segments used in this study, the observers underwent approximately 1-2 weeks of training with the joystick apparatus. The training started with a 5-h long introductory session, in which all the three observers participated. In this session, the trainer first introduced the observers to the basic interpersonal theoretical idea that people's interpersonal behaviors could be organized around the orthogonal axes of dominance-submissiveness and friendliness-hostility. Then, the observers familiarized with the computer joystick apparatus and practiced moving the joystick smoothly in different directions. Next, the observers engaged in three "offline" exercises, whose purpose was to train the observers to incorporate their newly acquired knowledge of interpersonal theory to the concrete ways they would move the computer joystick, as well as to facilitate discussion on the topic. First, in line with the training protocol developed by Sadler et al. [61], the observers were instructed to move the joystick to the correct location in the Cartesian plane in response to 16 interpersonal adjectives, such as warm, trusting, passive, unsociable, indifferent, critical, assertive and outgoing. Then, the observers carried out a similar exercise with images of facial expressions; the images were drawn from the study by Myllyniemi [50], who has shown that the idea of the interpersonal circumplex applies also to facial expressions of emotion. Finally, the observers heard one-sentence-long verbal descriptions of interactional events, in response to which they needed to move the joystick to the correct location in the Cartesian plane (see "Appendix"). After the observers had successfully completed these three offline exercises, they started practicing the "online" rating of the interaction data, with 
the trainer monitoring each observer's performance and discussing any problems or questions as they arose.

After the joint training session, each observer practiced the joystick method independently by rating ten 3-min-long video segments of interactions not included in the actual study. The observers were told to base the ratings on their intuitions, since we regarded this as the only way for them to be able to reach immediate rating decisions in the constant flow of interaction, given the possibility of multiple simultaneous behaviors, whose relative interpersonal importance at a specific moment of interaction cannot be predetermined. On a larger scale, however, the rating decisions were expected to be in line with the more traditional interpersonal measures, such as one described by Moskowitz [48], where dominance is described with reference to items such as "I expressed opinion", "I criticized the other" and "I spoke in a clear firm voice", and affiliation with reference to items such as "I showed sympathy", "I smiled and laughed with the other", "I expressed affection with words or gestures". The observers were told not to rate more than 1-2 segments a day so that they would be able to maximally concentrate on the task. When the observers had completed their training, they started to rate the interaction segments used in the study. The inter-observer reliability as assessed with Cronbach's alpha [17] of the raters was $\alpha=0.82$ for female dyads and $\alpha=0.75$ for male dyads with respect to affiliation, and $\alpha=0.98$ for female dyads and $\alpha=0.95$ for male dyads with respect to dominance. Overall, the joystick-derived indices of affiliation and dominance were highly reliable. Since in our video materials the indices of dominance were strongly associated with specific features of the participants' verbal conduct, their reliable detection seemed to be particularly easy for the observers.

\section{Procedure for Obtaining Observer Ratings}

For each video-recorded interaction episode included in the study $(n=16)$, we examined two 10-min segments: one from the beginning of the conversation and the other from the end of it. The three trained observers used the computer-joystick device to provide continuous, moment-to-moment rating of each participant's behavior throughout the course of the interaction segments. Thus, given that, for each conversation, there were two participants and two segments to rate, each observer needed to completer altogether $(16 \times 2 \times 2) 64$ separate 10 -min-long rating tasks $(10 \mathrm{~h}$ $40 \mathrm{~min}$ in total). These tasks were presented for each participant in a different randomized order. What we controlled for, however, was that two participants from the same dyad and interaction segment were never rated consecutively.

At the beginning of each rating task, the observer pressed the start button for the joystick to start the playing of the video segment. Then, by moving the joystick appropriately for the next $10 \mathrm{~min}$, the observer provided a continuous rating of the target person in the two-dimensional Cartesian space, which represented the two axes of the interpersonal circumplex: dominance-submission and hostility-friendliness. For the sake of simplicity, we will henceforth refer to these two dimensions of interpersonal behavior as affiliation (x-axis) and dominance (y-axis). 


\section{Data Processing and Analyses}

To cancel out any idiosyncrasies of the individual raters, the moment-to-moment ratings of the three observers were aggregated by computing the average at each time point. The resulting data from each rated data segment yielded two key bivariate time series: one for the participants' levels of affiliation over time, and another for the participants' levels of dominance over time. The resulting time series had a duration of $600 \mathrm{~s}$ or 1800 data points (3 samples per second). Statistical data were preprocessed with Matlab and further analyzed with SPSS 23.0.

First, we examined whether we could observe the same patterns of complementarity that have been discussed in much theoretical and empirical research literature on interpersonal behavior. In particular, we wanted to assess whether there would be differences between females and males ('Gender') and/or between the beginning and end phases of conversation ('Phase') in this regard. For each participant, we (1) calculated the mean levels of observed affiliation and dominance ('Affiliation mean', 'Dominance mean') during the beginning and end phases of conversation. Then, for each dyad, we assessed (2) the bivariate time series relating the two participants' moment-to-moment affiliative and dominant interpersonal behaviors. As indices of interrelatedness in such time series, we calculated two variables: the 'Zero-lag cross-correlation' and the 'Average weighted coherence' [56]. These calculations were done separately for affiliation and dominance, on the one hand, and for the beginning and end phases of conversation, as well as for both phases together, on the other.

To analyze complementarity in the participants' overall affiliative and dominant behaviors, we built separate mixed models with affiliation and dominance as the outcome variable. In the models, gender was estimated as a fixed effect. ${ }^{2}$ To control for the dyadic structure of the data, the co-participant's affiliation/dominance score was included as a covariate in the model. Dyad was included as a repeated measures effect and estimated with CS covariance model. Estimates will be reported as standardized betas and indicate effect sizes. To examine the participants' momentto-moment affiliative and dominant interpersonal behaviors, we used standard general linear models similar to those described above, but with a dyad as the unit of analysis. Separate models were built for the zero-lag cross-correlations and the average weighted coherence values in the bivariate time series relating the two participants' moment-to-moment levels of affiliation and dominance with gender included as a fixed effect.

Secondly, we were interested in the experiential consequences of dominance and affiliation. We built separate mixed models for four different outcome variables:

\footnotetext{
${ }^{2}$ We used gender as a fixed effect for several reasons. Primarily, the choice was made for statistical reasons. As dyads are comprised of equal genders, gender here can be seen as constant and not varying within dyad. Statistical models used here refer to the dyad as the unit of the analysis to account for the internal dependency issues inherent in dyadic data. Additionally, we used the interaction of gender with the other independent variables to test our hypotheses on group differences. This necessitates to estimate gender as a fixed variable, in order to be able to estimate different effects for the two groups. Finally, none of our participants reported being outside the binary female/male classification of gender.
} 
'Happiness', 'Anxiety', 'Valence Change', and 'Arousal Change'. The variables Happiness and Anxiety are sum variables computed from a set of PANAS items, included in the post conversation questionnaire (see above). The variables Valence Change and Arousal Change were calculated by subtracting the SAM affect scale scores in the pre-conversation questionnaire from those in the post-conversation questionnaire (see above).

The experiential consequences of dominance and affiliation were assessed with reference to both the participants' overall mean levels of observed affiliation/dominance and the dyad-specific moment-to-moment affiliation synchrony or dominance coordination, as measured by cross correlations and average weighted coherence values. In the mixed models using the predictor variables of the former type, we controlled for the dyadic structure of the data by including the co-participant's mean affiliation/dominance score as a covariate in the model. In the mixed models built with reference to the affiliation/dominance cross correlations and average weighted coherence values, both affiliation and dominance, as well as their interaction, served as predictor variables. In all models, Gender and its interactions with independent predictors were included as a fixed factor.

Initially, we ran separate models for the two phases of conversation ('Beginning', 'End'), as well as for their combination ('Grand mean'). However, as the beginning and end segments exhibited mostly similar effects on the experiential outcome variables to be discussed, we will report here mainly the results with the grand mean.

\section{Results}

\section{Assessing Complementarity Through the Patterns of Affiliation and Dominance}

(1) To consider the level of complementarity in the participants' overall affiliative and dominant behaviors, we considered affiliation and dominance separately. In line with the key insights of interpersonal theory, we found that the mean affiliation score was positively affected by the co-participants' mean affiliation score, while the mean dominance score was negatively affected by the co-participants' mean dominance score. Both of these effects were statistically highly significant (see Table 1 in the "Appendix"). Interestingly, there were no differences between the two genders in the participants' tendency to engage in complementary behaviors.

(2) To analyze the level of complementarity in the participants' moment-tomoment affiliative and dominant interpersonal behaviors, we examined the indices of interrelatedness in the two participants' affiliation/dominance time series. Again, consistent with the notion of complementarity, the participants' moment-to-moment levels of affiliation correlated positively (range $0.21-0.68$, mean $=0.44, \mathrm{SD}=0.15$ ). The mean of the correlations was significantly greater than zero $[\mathrm{t}(15)=11.84$, $p<0.001]$. Dyad mean was also higher compared to pseudo-distribution of all unrelated dyads $[\mathrm{t}(3214)=15.03, p<0.001$; calculated by using the beginning phases of conversation]. Also consistent with the notion of complementarity, the participants' moment-to-moment levels of dominance were negatively correlated (range -0.95 to -0.57 , mean $=-0.83, \mathrm{SD}=0.10$ ). The mean of the correlations was 
significantly less than zero $[\mathrm{t}(15)=-32.39, p<0.001]$ and greater than the mean of pseudo-distribution [t(15.40) $=-31.64, p<0.001]$. Supporting these patterns, the means of the average weighted coherence values indicated substantial overall attunement of cycles between the participants (affiliation: range 0.33-0.73, mean $=0.55$, $\mathrm{SD}=0.11$; dominance: range $0.63-0.98$, mean $=0.87, \mathrm{SD}=0.10$ ). Also here, all comparisons to zero and pseudo-distributions were significant at $p<0.001$ level. Thus, overall these results yielded strong support for the complementarity so that affiliation levels were positively associated and dominance levels negatively associated among the interaction participants (Table 1).

Yet, here, too, we found no statistically significant differences between females and males in the moment-to-moment matching of affiliative and dominant behaviors. Furthermore, we found no differences between the beginning and end phases of conversation.

\section{Experiential Consequences of Dominant and Affiliative Behavioral Patterns}

\section{Consequences of Affiliation on the Experience of Conversation}

Preliminary analysis was conducted to test whether there were differences in group means of Gender for the dependent variables. All comparisons were found to be nonsignificant $(p>0.19)$.

We first considered the effect of the participants' overall mean levels of affiliation on the outcome variables (see Table 2 in the "Appendix"). Happiness tended to increase if the co-participant was affiliative $[\mathrm{b}=0.29, \mathrm{SE}=0.31 ; \mathrm{F}(1,21.99)=3.64$, $p=0.070$, power $=0.33$ ]. Self-expressed affiliation, in contrast, tended to lead to a decreased level of experienced happiness $[\mathrm{b}=-0.53, \mathrm{SE}=0.31 ; \mathrm{F}(1,21.99)=4.14$, $p=0.054$, power $=0.79]$.

We then examined the effect of the moment-to-moment affiliation synchrony for the experiential outcomes of the dyad, measured as mean scores of the two participants' individual scores (see Tables 4, 5 in the "Appendix"). We found a statistically significant interaction between gender and affiliation weighed coherence with respect to experienced happiness $\left[\mathrm{F}(1,9)=7.21, p<0.05, \eta^{2}=0.45\right.$, power $\left.=0.67\right]$ : in males, affiliation synchrony was associated with an increase in happiness $(b=0.46$, $\mathrm{SE}=0.34)$, whereas in females the effect was in the opposite direction $(b=-0.80$, $\mathrm{SE}=0.32$; see Fig. 2a). Furthermore, we found that a high degree of affiliation synchrony during the end phase of the conversation increased the level of arousal for males $(b=1.11, S E=0.25)$, but did less so for females $[b=0.31, S E=0.22$, $\mathrm{F}(1,9)=5.79, p<0.05, \eta^{2}=0.39$, power $=0.57$; see Fig. $\left.2 \mathrm{~b}\right]$.

There were no significant effects of affiliation on experienced valence change and anxiety.

\section{Consequences of Dominance on the Experience of Conversation}

Considering the effect of participants' overall mean levels of dominance, we found that the levels of arousal in the participants were positively affected both 

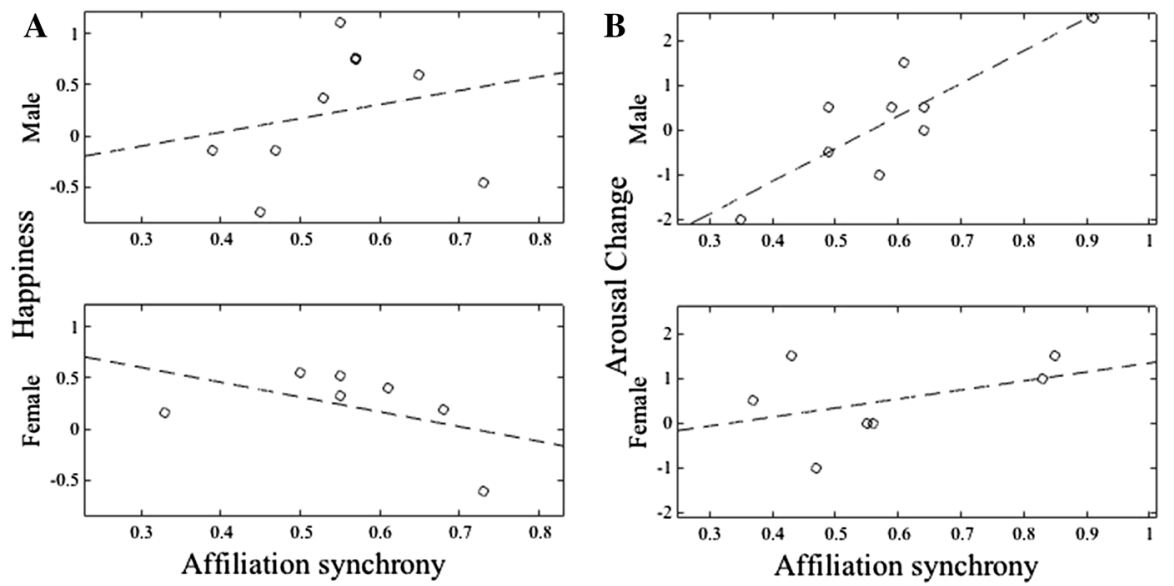

Fig. 2 a The effect of affiliation synchrony (wcoh; grand means) on happiness for females and males. b The effect of affiliation synchrony (wcoh; late) on arousal change for females and males

by self-expressed dominance $[\mathrm{b}=1.01, \mathrm{SE}=0.50 ; \mathrm{F}(1,13.47)=11.14, p<0.01$, power $=0.70]$ and partner dominance $[\mathrm{b}=1.08, \mathrm{SE}=0.50 ; \mathrm{F}(1,13.47)=11.90$, $p<0.01$, power $=0.76$ ] during the beginning phase of conversation (see Table 3 in the "Appendix"). The same results were obtained also in the analysis of grand means containing both the beginning and end phases of conversation, but the effect was stronger for the beginning phase of conversation.

The participants' increased levels of valence were predicted by their co-participants' levels of dominance [analysis of grand means: $b=1.63, S E=0.54$; $\mathrm{F}(1,14.05)=6.14, p<0.05$, power $=0.99$ ]. Here we noted two gender-specific effects. Self-dominance during the beginning phase of conversation had a positive effect on valence change for females, but less so for males [for females: $\mathrm{b}=1.10, \mathrm{SE}=0.44 ; \mathrm{F}(1,13.84)=4.84, p<0.05$, power $=0.92]$. In line with that, partner-dominance during the beginning phase of conversation had a positive effect on Valence change for females, but less so for males [for females: $b=1.57$, $\mathrm{SE}=0.44 ; \mathrm{F}(1,13.84)=7.35, p<0.05$, power $=0.99]$. In sum, this suggests that the above-described valence-increasing effect of co-participant's dominance is stronger for females than for males, and that this difference is greater for the beginning of conversation than for the end of it.

(2) As for the participants' moment-to-moment coordination of dominance, we found an effect on Valence change that differed for the genders: using the average weighted coherence values of the dominance bivariate time series (grand means), a high level of moment-to-moment coordination of dominance predicted a more negative change in valence for females than for males [for females: $b=-1.29$, $\mathrm{SE}=0.47, \mathrm{~F}(1,9)=4.61, p=0.060, \eta^{2}=0.34$, power $=0.48$; see Fig. 3 and Tables 4, 5 in the "Appendix"].

There were no effects of dominance on the experienced happiness or anxiety. 
Fig. 3 The effect of dominance coordination (wcoh; grand means) on valence change for females and males

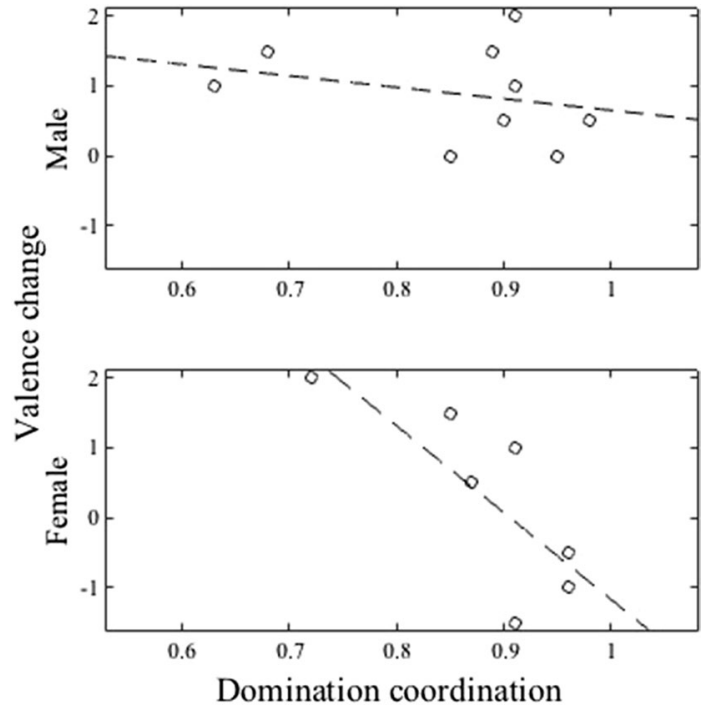

\section{Discussion}

In this study, we examined dyadic same-gender conversations between unacquainted participants using the joystick method developed by Sadler et al. [61]. More specifically, we investigated patterns of the participants' affiliative and dominant behaviors during the first and last ten minutes of these conversations, considering the consequences of these patterns for the experiences of female and male participants.

First, we hypothesized that the patterns of dominant and affiliative behavior would differ for the early and late phases of conversation. While conversations between strangers particularly clearly governed by a range of normative expectations $[46,69,70]$, we assumed such expectations to be stronger during the beginning segment of conversation than during its end segment. Thus, with reference to the notion of complementarity proposed by the interpersonal theorists [11, 32, 76, 82], we expected that the participants would be particularly keen to match each other's affiliative behaviors and to display opposite behaviors on the dominance dimension at the beginning of conversation. But then again, with reference to the notion of behavioral convergence over time [20, 43, 51, 52], we also considered the alternative possibility that participants would need some time to adjust to each other's characteristic ways of expressing of affiliation and dominance. From this point of view, we thought that the patterns of complementarity could be stronger during the end segments of conversation than during their beginning segments. Now, however, given that our data did not demonstrate any statistically significant differences in the patterns of complementarity between the beginning and end phases of conversation, we cannot make definite conclusions in favor of either of these two views. Weak support for the first hypothesis was, however, provided by the fact that we found a weak trend for affiliation synchrony (zero-lag cross-correlations) to decrease from 
the beginning phase of conversation to its end phase. Even if this result is not very robust it is in line with some of the other results to be discussed further below.

We also asked whether the patterns of affiliation and dominance would exhibit gender differences. Given the great amount of literature pointing to social-interaction-related gender differences $[12,38]$, we expected to find something along the same lines. More specifically, drawing on the insights of some interpersonal theorists and others $[3,8,9,18]$, we expected that females would express affiliation more than males and also match each other's affiliative behaviors on a momentby-moment basis more precisely than males. We also anticipated that males would overall display more dominance than females and coordinate their dominant behaviors more accurately than females. Indeed, given the previous findings according to which gender differences would be maximized in situations of high stress, which we thought to hold also for the first conversations in our research setting, we expected such gender differences to be relatively strong. To our surprise, however, we did not find any statistically significant gender differences in the observed patterns of interpersonal behaviors displayed by the participants in our data. Of course, this does not tell us anything about the existence of gender differences in cross-gender dyads. Though, in an earlier study on cross-gender dyads by Sadler et al. [61], the researchers found no gender differences (except for a higher affiliation intercept for females than males). This, along with the findings of our study, suggests that the complementary patterns of affiliation and dominance, which largely characterize normal everyday interactions, are basically gender-neutral.

Importantly, however, we did not only study patterns of interpersonal behavior, but also explored the experiential outcomes of such patterns. We asked about the relationship of the participants' dominant and affiliative behaviors to happiness and anxiety and changes in valence and arousal. On the basis of earlier findings on partner-affiliation and emotional experience [55], we anticipated that partner-affiliation would increase the levels of positive valence and happiness and decrease the levels of arousal and anxiety in the participants. This notion was supported by our data. We found that partner-affiliation during the end phase of conversation decreased the level of anxiety reported by the participants in the post conversation questionnaire. The matter that this effect was found only with reference to the end phases of conversation suggests that the scope of the anxiety-reducing effect of partner-affiliation may be relatively short-term and local. In other words, after the conversation (when the outcome was measured), what matters for anxiety is the interactional pattern just prior to the termination of the encounter, not so much what happened earlier in the conversation. In line with our anticipations, we also found partner-affiliation to increase the level of happiness. Interestingly, however, we found self-expressed affiliation to decrease the level of happiness. Thus, even if our findings confirm the crucial importance of partner-affiliation for the participants' positive interactional experience, they also show that this does not happen without a cost. In line with what Hochschild [29, 30] has vividly argued, expressing affiliation can be draining work, which may have a negative effect on one's own well-being. Expressing affiliation involves taking on a "load" of emotion [55] also in this respect.

We did not formulate any specific hypotheses regarding the experiential outcomes of dominance. Dominance, however, turned out to be an important predictor 
of arousal; it was increased both by self-expressed dominance and partner-dominance. Notably, this effect was related only to the beginning phase of conversation, which makes sense in light of the first conversations being particularly vulnerable at their very beginning. Dominant behavior in terms of active engagement during the beginning phase of conversation could thus create a particularly intensive and longlasting experiential effect. Moreover, partner-dominance also predicted an increased positive change in valence. This effect was related both to the beginning and end phases of conversation. Again, the result may be best explained with reference to the particularities of conversations between two strangers. At least to the extent that dominance is associated with concrete behaviors such as deciding on topics of conversation by engaging in interrogative behavior or carrying responsibility for the maintenance of the flow of conversation by providing extended responses to questions [70] it is understandable that the participants may feel good in realizing that their co-participants are active in contributing to the joint endeavor: the conversation. Here, however, we found an interesting gender-difference: self-dominance had a more negative effect on the valence of females than on that of males, and, in line with that, partner-dominance had a more positive effect on the valence of females than on that of males. These results - in line with some previous studies $[26,35]-$ suggest that the success of a conversation as a joint endeavor may possibly be a "bigger deal" for females than for males.

In addition, we considered the experiential consequences of affiliation synchrony and dominance coordination. Drawing on interpersonal theory, according to which complementary behavior confirms self-concepts, we hypothesized that the maximum levels of happiness and the minimum levels of anxiety would be driven by the moment-by-moment sameness in affiliation and oppositeness in dominance. Here, however, we found interesting gender differences. For males, affiliation synchrony was associated with an increase in happiness, but for females, it was associated with a decrease in happiness. Furthermore, a high degree of affiliation synchrony during the end phase of the conversation increased the level of arousal for males but not for females. This suggests the possibility of there being important differences in how affiliation synchrony is experienced by females and males. To the extent that affiliation synchrony indeed makes men both happier and more aroused than women, this could be explained with reference to a more pervasive engagement associated with male affiliation synchrony and a more obligation-oriented emotional reciprocity associated with female affiliation synchrony; while the former increases happiness and arousal, the latter does not do so (or even decreases the level of happiness). Such an idea is in agreement with earlier studies pointing to women being inclined to display positive emotions just to strive to relieve social tensions [29, 30]. While it is beyond the scope of this paper to provide an account for why such gender differences may exist, we still assume that the ways in which men and women are taught to socialize might play a central role in this regard.

As for dominance coordination, we found that a high level of moment-to-moment coordination of dominance decreased the valence for females, but not for males. To interpret this finding, we need to consider the kinds of interactional behaviors that would most likely create patterns of high dominance coordination. As discussed above, one regular characteristic of first conversations is that its participants engage 
in interrogative behavior [69]. During question-answer sequences, the participants' roles in contributing to the conversation are asymmetric-first, I am more of an actor than you are, then you are more of an actor than I am [19] — and these alternating speaker-recipient roles are likely to generate a neat complementary pattern in the participants' dominant behaviors. Our results suggest that this kind of pattern may be no problem for the interaction experiences of males. However, in line with other research, which has pointed to the less rigid turn-taking rules in all-female groups $[14,84]$, our results suggest that a too tight moment-by-moment dominance coordination could be a problem for females. In other words, our results suggest that there could be important gender differences as to what the positive, solidarity-promoting interactional style described in the literature [71, 73] actually consist of. While for males, this notion may be more closely linked to alternating dominance roles, for females it may be more essential to break such neat alternation.

Finally, in contrast to the above-discussed findings where the association between a positive interactional experience and a lack of complementarity was related to females, and not to males, our last finding is more gender-neutral. We found that, for both genders, the highest level of happiness could be predicted by the combination of both low affiliation synchrony and low dominance coordination. This suggests that the idea of discoordination feeling good may be a more generic feature of people's interaction experiences than has been regularly assumed. At the first sight, this idea appears to be in contradiction with the famous notions of Goffman [21], Collins [16], and many others, who have emphasized the importance of smooth coordination in interaction rituals as a precondition of positive interaction experiences that increase the participants" "emotional energy" [16]. But then again, to put on a show of participating wholeheartedly in interaction rituals, is particularly draining [80, p. 53). Also, as has been pointed out by some developmental psychologists, high coordination involves excessive monitoring, or "vigilance," an effort by both partners to create more moment-to-moment predictability of behavior, but it leaves less room for initiative, and flexibility within the experience of contingency and may thus lead to less than optimal relationship outcomes [31]. This study has shown that the same pattern holds also for adult interactions and for the immediate experiential consequences of these interactions.

The study has several limitations. First, our experiential measures draw on selfreport data, which can create common method bias [65]. We have sought to minimize this bias by explaining the participants the purpose of the study and ensuring their confidentiality. Second, our sample size is relatively small, which may limit the extent to which we can generalize the results. Third, we were not able to control for the content of the participants' conversations, which might have influenced some of our results. We nevertheless checked that there were no significant differences in how females and males generally rated their interactional experiences, which points to a relative similarity in the affective content of the conversations in the two types of dyads. Fourth, our results may have been impacted by self-selection bias. The sample for this research consists of volunteers socially courageous enough to decide to participate in a study where one is expected to be talking with a stranger. We may thus expect that those who find such situations particularly stressful were not likely to volunteer in our study, which may tilt the interactional experiences of our 
participants toward the positive end of the valence scale. Furthermore, the fact that the participants were strangers to each other is likely to have generated behavioral and experiential patterns that would be different in interactions between everyday acquaintances, friends, or family members-let alone the inevitable fact that the conversations were conducted for research purposes in the presence of video cameras. ${ }^{3}$ Finally, our findings about the relative similarity in the interpersonal behavioral features of the male and female participants in the same-gender should not be taken to mean that such behavioral differences could not be observed in cross-gender dyads. Also, the experiential consequences of behavioral patterns might be different depending on whether the participants are in same-gender or cross-gender dyadssomething that future research should address.

\section{Conclusions}

Overall, our study points to important gender-related differences, not in the patterns of interactional behaviors per se, but in the experiential consequences of these patterns. This highlights the necessity to take the study of the relationship between interaction patterns and gender differences in the experience of these patterns into the official agenda of empirical interaction research. Importantly, the paper suggests that, at least for females, a lack of "neat" complementarity in affiliation and/or dominance may be an important aspect of a positive interaction experience. This suggests a need to revisit previous male-centered social-scientific theorizing on the topic and calls for further research on the precise conditions in which different interactional patterns lead to different experiential outcomes.

Acknowledgements This research was supported by the Finnish Center of Excellence in Intersubjectivity in Interaction and by the Academy of Finland (Grants Number 274735 and 284595).

\section{Compliance with Ethical Standards}

Conflict of interest The authors declare that they have no conflict of interest.

Informed Consent The research involved human participants, who were informed about the use of the data and signed a consent form.

Open Access This article is distributed under the terms of the Creative Commons Attribution 4.0 International License (http://creativecommons.org/licenses/by/4.0/), which permits unrestricted use, distribution, and reproduction in any medium, provided you give appropriate credit to the original author(s) and the source, provide a link to the Creative Commons license, and indicate if changes were made.

\footnotetext{
${ }^{3}$ During the last decades, along with the rise of visual sociology and conversation analysis, there has been considerable discussion on whether and how video recording influences participants' interactional conduct $[15,41,57,77]$. What we see to be the overall consensus from these discussions is that, at the beginning of an interactional encounter, the presence of a video camera frequently involves the participants establishing a shared perception of the recording situation. After that, however, the participants tend to move on and engage normally with each other, immersed in the contingencies of moment-bymoment unfolding of interaction. This is also the impression that we got from our data.
} 


\section{Appendix}

See Tables 1, 2, 3, 4 and 5.

Table 1 Statistics of fixed effects predicting observed affiliation and dominance displayed by individual participants during the rated video segments (affiliation mean, dominance mean), as well as those predicting the moment-to-moment matching of affiliative and dominant behaviors between the participants in a dyad during the rated video segments (affiliation zero-lag cross-correlations/average weighted coherence, dominance zero-lag cross-correlations/average weighted coherence)

\begin{tabular}{|c|c|c|c|c|}
\hline Dependent variable & Effect & $\mathrm{F}$ & fi, $d f$ error & $p$ \\
\hline \multirow[t]{7}{*}{ Affiliation mean } & Gender & 0.220 & $1,18.49$ & 0.644 \\
\hline & Phase & 0.789 & $1,26.30$ & 0.382 \\
\hline & Gender $\times$ phase & 0.868 & $1,26.30$ & 0.360 \\
\hline & Partner affiliation mean & 10.004 & $1,47.89$ & $0.003 * *$ \\
\hline & Gender $\times$ partner affiliation mean & 0.264 & $1,47.89$ & 0.610 \\
\hline & Phase $\times$ partner affiliation mean & 0.053 & $1,34.61$ & 0.819 \\
\hline & $\begin{array}{l}\text { Gender } \times \text { phase } \times \text { partner affilia- } \\
\text { tion mean }\end{array}$ & 1.094 & $1,34.61$ & 0.303 \\
\hline \multirow[t]{7}{*}{ Dominance mean } & Gender & 0.085 & $1,19.16$ & 0.774 \\
\hline & Phase & 0.052 & $1,24.10$ & 0.822 \\
\hline & Gender $\times$ phase & 0.187 & $1,24.10$ & 0.669 \\
\hline & Partner dominance mean & 262.489 & $1,55.49$ & $0.000 * * *$ \\
\hline & Gender $\times$ partner dominance mean & 0.278 & $1,55.49$ & 0.600 \\
\hline & Phase $\times$ partner dominance mean & 0.033 & $1,50.05$ & 0.857 \\
\hline & $\begin{array}{l}\text { Gender } \times \text { phase } \times \text { partner domi- } \\
\text { nance mean }\end{array}$ & 0.220 & $1,50.05$ & 0.641 \\
\hline \multirow{3}{*}{$\begin{array}{l}\text { Affiliation zero-lag cross-corre- } \\
\text { lation }\end{array}$} & Gender & 0.081 & 1,14 & 0.781 \\
\hline & Phase & 2.609 & 1,14 & 0.129 \\
\hline & Gender $\times$ phase & 0.565 & 1,14 & 0.465 \\
\hline \multirow{3}{*}{$\begin{array}{l}\text { Affiliation average weighted } \\
\text { coherence }\end{array}$} & Gender & 0.098 & 1,14 & 0.759 \\
\hline & Phase & 1.622 & 1,14 & 0.223 \\
\hline & Gender $\times$ phase & 0.230 & 1,14 & 0.639 \\
\hline \multirow{3}{*}{$\begin{array}{l}\text { Dominance zero-lag cross- } \\
\text { correlation }\end{array}$} & Gender & 0.028 & 1,14 & 0.869 \\
\hline & Phase & 1.765 & 1,14 & 0.205 \\
\hline & Gender $\times$ phase & 0.001 & 1,14 & 0.971 \\
\hline \multirow{3}{*}{$\begin{array}{l}\text { Dominance average weighted } \\
\text { coherence }\end{array}$} & Gender & 0.283 & 1,14 & 0.603 \\
\hline & Phase & 1.831 & 1,14 & 0.198 \\
\hline & Gender $\times$ phase & 0.000 & 1,14 & 0.983 \\
\hline
\end{tabular}

$* * * p<0.001 ; * * p<0.01 ; * p<0.05$ 
Table 2 The effects of the overall levels of affiliation on the experiential outcome variables: valence change, arousal change, happiness and anxiety

\begin{tabular}{|c|c|c|c|c|}
\hline Dependent variable & Effect & $\mathrm{F}$ & fi, $d f$ error & $p$ \\
\hline \multirow[t]{15}{*}{ Valence change } & Gender & 0.897 & $1,12.90$ & 0.361 \\
\hline & Affiliation mean (beginning) & 0.112 & $1,21.94$ & 0.741 \\
\hline & Partner affiliation mean (beginning) & 0.890 & $1,21.94$ & 0.356 \\
\hline & Gender $\times$ affiliation mean (beginning) & 0.019 & 121.94 & 0.893 \\
\hline & Gender $\times$ partner affiliation mean (beginning) & 0.0 .569 & $1,21.94$ & 0.459 \\
\hline & Gender & 1.400 & $1,12.30$ & 0.259 \\
\hline & Affiliation mean (end) & 2.469 & $1,21.92$ & 0.130 \\
\hline & Partner affiliation mean (end) & 0.656 & $1,21.92$ & 0.427 \\
\hline & Gender $\times$ affiliation mean (end) & 1.059 & $1,21.92$ & 0.315 \\
\hline & Gender $\times$ partner affiliation mean (end) & 0.344 & $1,21.92$ & 0.564 \\
\hline & Gender & 1.173 & 1,12 & 0.300 \\
\hline & Affiliation mean (grand mean) & 1.161 & $1,22.32$ & 0.293 \\
\hline & Partner affiliation mean (grand mean) & 1.140 & $1,22.32$ & 0.297 \\
\hline & Gender $\times$ affiliation mean (grand mean) & 0.425 & $1,22.32$ & 0.521 \\
\hline & Gender $\times$ partner affiliation mean (grand mean) & 0.771 & $1,22.32$ & 0.389 \\
\hline \multirow[t]{15}{*}{ Arousal change } & Gender & 0.017 & $1,12.53$ & 0.899 \\
\hline & Affiliation mean (beginning) & 0.002 & $1,24.97$ & 0.963 \\
\hline & Partner affiliation mean (beginning) & 1.231 & $1,24.97$ & 0.278 \\
\hline & Gender $\times$ affiliation mean (beginning) & 0.031 & $1,24.97$ & 0.862 \\
\hline & Gender $\times$ partner affiliation mean (beginning) & 0.178 & $1,24.97$ & 0.677 \\
\hline & Gender & 0.205 & $1,12.22$ & 0.658 \\
\hline & Affiliation mean (end) & 0.345 & $1,23.78$ & 0.562 \\
\hline & Partner affiliation mean (end) & 0.374 & $1,23.78$ & 0.547 \\
\hline & Gender $\times$ affiliation mean (end) & 1.860 & $1,23.78$ & 0.185 \\
\hline & Gender×partner affiliation mean (end) & 0.002 & $1,23.78$ & 0.965 \\
\hline & Gender & 0.090 & 1,12 & 0.769 \\
\hline & Affiliation mean (grand mean) & 0.085 & $1,24.50$ & 0.773 \\
\hline & Partner affiliation mean (grand mean) & 0.699 & $1,24.50$ & 0.411 \\
\hline & Gender $\times$ affiliation mean (grand mean) & 0.555 & $1,24.50$ & 0.463 \\
\hline & Gender $\times$ partner affiliation mean (grand mean) & 0.037 & $1,24.50$ & 0.849 \\
\hline
\end{tabular}


Table 2 (continued)

\begin{tabular}{|c|c|c|c|c|}
\hline Dependent variable & Effect & $\mathrm{F}$ & fi, $d f$ error & $p$ \\
\hline \multirow[t]{15}{*}{ Happiness } & Gender & 0.028 & $1,12.87$ & 0.869 \\
\hline & Affiliation mean (beginning) & 2.667 & $1,22.16$ & 0.117 \\
\hline & Partner affiliation mean (beginning) & 4.666 & $1,22.16$ & $0.042 *$ \\
\hline & Gender $\times$ affiliation mean (beginning) & 0.390 & $1,22.16$ & 0.539 \\
\hline & Gender $\times$ partner affiliation mean (beginning) & 0.603 & $1,22.16$ & 0.446 \\
\hline & Gender & 0.003 & $1,12.35$ & 0.960 \\
\hline & Affiliation mean (end) & 2.793 & $1,21.02$ & 0.109 \\
\hline & Partner affiliation mean (end) & 1.434 & $1,21.02$ & 0.244 \\
\hline & Gender $\times$ affiliation mean (end) & 0.217 & $1,21.02$ & 0.646 \\
\hline & Gender $\times$ partner affiliation mean (end) & 0.027 & $1,21.02$ & 0.870 \\
\hline & Gender & 3.007 & 1,12 & 0.994 \\
\hline & Affiliation mean (grand mean) & 0.000 & $1,21.99$ & 0.054 \\
\hline & Partner affiliation mean (grand mean) & 4.139 & $1,21.99$ & 0.070 \\
\hline & Gender $\times$ affiliation mean (grand mean) & 3.640 & $1,21.99$ & 0.573 \\
\hline & Gender $\times$ partner affiliation mean (grand mean) & 0.327 & $1,21.99$ & 0.644 \\
\hline \multirow[t]{15}{*}{ Anxiety } & Gender & 0.863 & $1,12.40$ & 0.371 \\
\hline & Affiliation mean (beginning) & 0.499 & $1,25.89$ & 0.486 \\
\hline & Partner affiliation mean (beginning) & 0.084 & $1,25.89$ & 0.775 \\
\hline & Gender $\times$ affiliation mean (beginning) & 0.022 & $1,25.89$ & 0.884 \\
\hline & Gender $\times$ partner affiliation mean (beginning) & 0.221 & $1,25.89$ & 0.642 \\
\hline & Gender & 1.463 & $1,12.160$ & 0.249 \\
\hline & Affiliation mean (end) & 0.010 & $1,25.30$ & 0.919 \\
\hline & Partner affiliation mean (end) & 4.148 & $1,25.30$ & 0.052 \\
\hline & Gender $\times$ affiliation mean (end) & 1.219 & $1,25.30$ & 0.280 \\
\hline & Gender $\times$ partner affiliation mean (end) & 0.225 & $1,25.30$ & 0.639 \\
\hline & Gender & 1.514 & 1,12 & 0.242 \\
\hline & Affiliation mean (grand mean) & 0.047 & $1,25.73$ & 0.831 \\
\hline & Partner affiliation mean (grand mean) & 1.573 & $1,25.73$ & 0.221 \\
\hline & Gender $\times$ affiliation mean (grand mean) & 0.237 & $1,25.73$ & 0.630 \\
\hline & Gender $\times$ partner affiliation mean (grand mean) & 0.004 & $1,25.73$ & 0.952 \\
\hline
\end{tabular}

$* * * p<0.001 ; * * p<0.01 ; * p<0.05$ 
Table 3 The effects of the overall levels of dominance on the experiential outcome variables: valence change, arousal change happiness and anxiety

\begin{tabular}{|c|c|c|c|c|}
\hline Dependent variable & Effect & $\mathrm{F}$ & fi, $d f$ error & $p$ \\
\hline \multirow[t]{15}{*}{ Valence change } & Gender & 2.649 & $1,12.72$ & 0.128 \\
\hline & Dominance mean (beginning) & 1.014 & $1,13.84$ & 0.331 \\
\hline & Partner dominance mean (beginning) & 3.542 & $1,13.84$ & 0.081 \\
\hline & Gender $\times$ dominance mean (beginning) & 4.844 & $1,13.84$ & $0.045^{*}$ \\
\hline & Gender $\times$ partner dominance mean (beginning) & 7.347 & $1,13.84$ & $0.017 *$ \\
\hline & Gender & 1.982 & $1,12.76$ & 0.183 \\
\hline & Dominance mean (end) & 1.093 & $1,13.28$ & 0.314 \\
\hline & Partner dominance mean (end) & 1.895 & $1,13.28$ & 0.191 \\
\hline & Gender $\times$ dominance mean (end) & 0.007 & $1,13.28$ & 0.935 \\
\hline & Gender $\times$ partner dominance mean (end) & 0.052 & $1,13.28$ & 0.823 \\
\hline & Gender & 2.371 & 1,12 & 0.150 \\
\hline & Dominance mean (grand mean) & 0.789 & $1,14.05$ & 0.095 \\
\hline & Partner dominance mean (grand mean) & 0.868 & $1,14.05$ & $0.026^{*}$ \\
\hline & Gender $\times$ dominance mean (grand mean) & 10.004 & $1,14.05$ & 0.153 \\
\hline & Gender $\times$ partner dominance mean (grand mean) & 0.264 & $1,14.05$ & 0.095 \\
\hline \multirow[t]{15}{*}{ Arousal change } & Gender & 0.372 & $1,12.58$ & 0.553 \\
\hline & Dominance mean (beginning) & 11.141 & $1,13.47$ & $0.005^{* *}$ \\
\hline & Partner dominance mean (beginning) & 11.904 & $1,13.47$ & $0.004 * *$ \\
\hline & Gender $\times$ dominance mean (beginning) & 0.479 & $1,13.47$ & 0.501 \\
\hline & Gender $\times$ partner dominance mean (beginning) & 0.407 & $1,13.47$ & 0.534 \\
\hline & Gender & 0.141 & $1,12.44$ & 0.714 \\
\hline & Dominance mean (end) & 0.811 & $1,12.73$ & 0.384 \\
\hline & Partner dominance mean (end) & 0.513 & $1,12.73$ & 0.487 \\
\hline & Gender $\times$ dominance mean (end) & 0.000 & $1,12.73$ & 0.993 \\
\hline & Gender $\times$ partner dominance mean (end) & 0.005 & $1,12.73$ & 0.944 \\
\hline & Gender & 0.166 & 1,12 & 0.690 \\
\hline & Dominance mean (grand mean) & 8.012 & $1,13.49$ & $0.014^{*}$ \\
\hline & Partner dominance mean (grand mean) & 7.700 & $1,13.49$ & $0.015^{*}$ \\
\hline & Gender $\times$ dominance mean (grand mean) & 0.056 & $1,13.49$ & 0.817 \\
\hline & Gender $\times$ partner dominance mean (grand mean) & 0.058 & $1,13.49$ & 0.813 \\
\hline
\end{tabular}


Table 3 (continued)

\begin{tabular}{|c|c|c|c|c|}
\hline Dependent variable & Effect & $\mathrm{F}$ & fi, $d f$ error & $p$ \\
\hline \multirow[t]{15}{*}{ Happiness } & Gender & 0.098 & $1,12.52$ & 0.760 \\
\hline & Dominance mean (beginning) & 0.829 & $1,13.32$ & 0.379 \\
\hline & Partner dominance mean (beginning) & 0.821 & $1,13.32$ & 0.381 \\
\hline & Gender $\times$ dominance mean (beginning) & 0.500 & $1,13.32$ & 0.492 \\
\hline & Gender $\times$ partner dominance mean (beginning) & 0.015 & $1,13.32$ & 0.905 \\
\hline & Gender & 0.000 & $1,12.90$ & 0.993 \\
\hline & Dominance mean (end) & 0.821 & $1,13.52$ & 0.381 \\
\hline & Partner dominance mean (end) & 0.657 & $1,13.52$ & 0.432 \\
\hline & Gender $\times$ dominance mean $(\mathrm{end})$ & 0.292 & $1,13.52$ & 0.597 \\
\hline & Gender $\times$ partner dominance mean (end) & 0.128 & $1,13.52$ & 0.726 \\
\hline & Gender & 0.001 & 1,12 & 0.982 \\
\hline & Dominance mean (grand mean) & 1.038 & $1,13.74$ & 0.326 \\
\hline & Partner dominance mean (grand mean) & 1.581 & $1,13.74$ & 0.230 \\
\hline & Gender $\times$ dominance mean (grand mean) & 0.686 & $1,13.74$ & 0.422 \\
\hline & Gender $\times$ partner dominance mean (grand mean) & 0.003 & $1,13.74$ & 0.958 \\
\hline \multirow[t]{15}{*}{ Anxiety } & Gender & 1.027 & $1,12.22$ & 0.330 \\
\hline & Dominance mean (beginning) & 0.585 & $1,12.56$ & 0.458 \\
\hline & Partner dominance mean (beginning) & 0.997 & $1,12.56$ & 0.337 \\
\hline & Gender $\times$ dominance mean (beginning) & 0.026 & $1,12.56$ & 0.875 \\
\hline & Gender $\times$ partner dominance mean (beginning) & 0.231 & $1,12.56$ & 0.639 \\
\hline & Gender & 1.589 & $1,12.47$ & 0.231 \\
\hline & Dominance mean (end) & 0.011 & $1,12.79$ & 0.917 \\
\hline & Partner dominance mean (end) & 0.025 & $1,12.79$ & 0.876 \\
\hline & Gender $\times$ dominance mean (end) & 4.122 & $1,12.79$ & 0.064 \\
\hline & Gender $\times$ partner dominance mean $(\mathrm{end})$ & 3.877 & $1,12.79$ & 0.071 \\
\hline & Gender & 1.304 & 1,12 & 0.276 \\
\hline & Dominance mean (grand mean) & 0.003 & $1,12.68$ & 0.958 \\
\hline & Partner dominance mean (grand mean) & 0.107 & $1,12.68$ & 0.749 \\
\hline & Gender $\times$ dominance mean (grand mean) & 1.229 & $1,12.68$ & 0.288 \\
\hline & Gender $\times$ partner dominance mean (grand mean) & 0.560 & $1,12.68$ & 0.468 \\
\hline
\end{tabular}

$* * * p<0.001 ; * * p<0.01 ; * p<0.05$ 


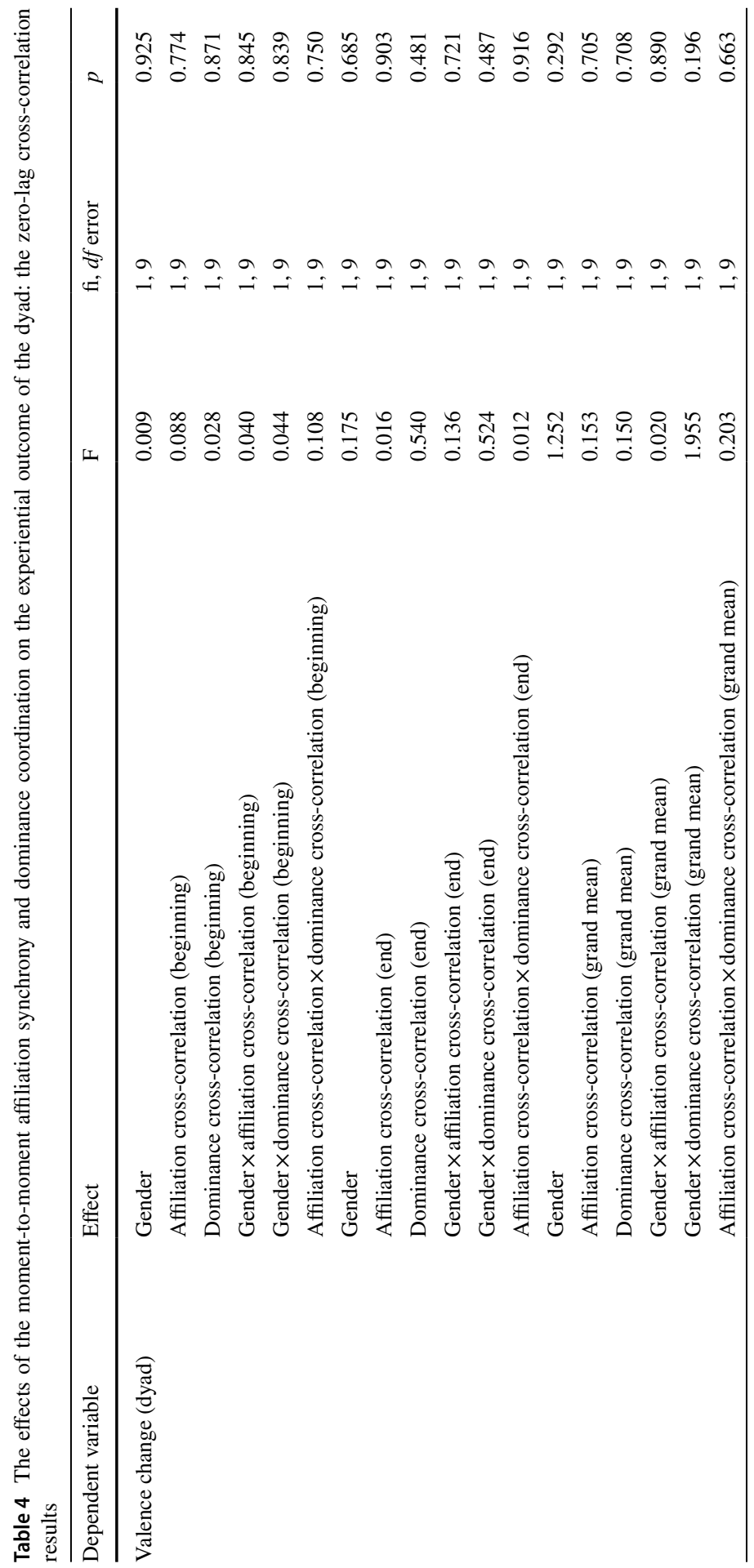




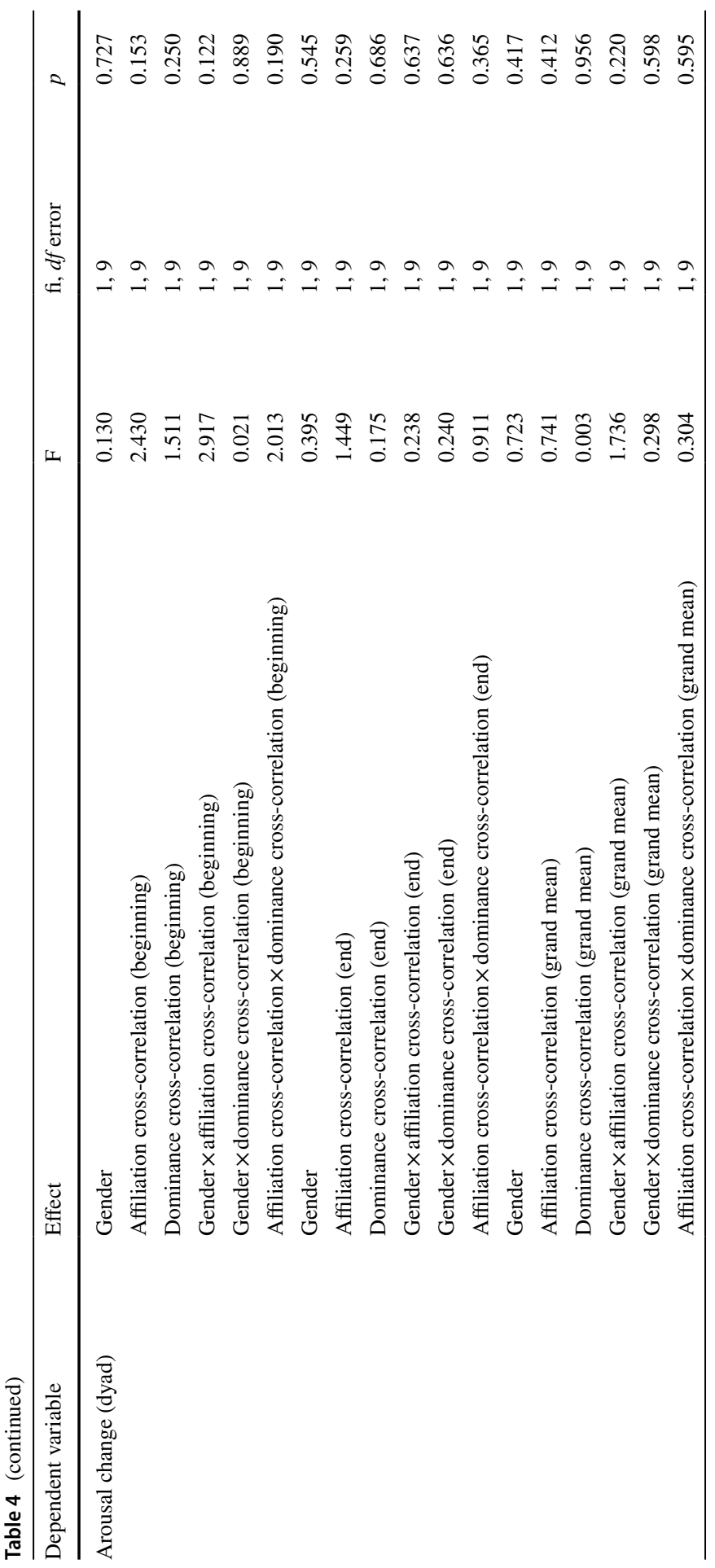




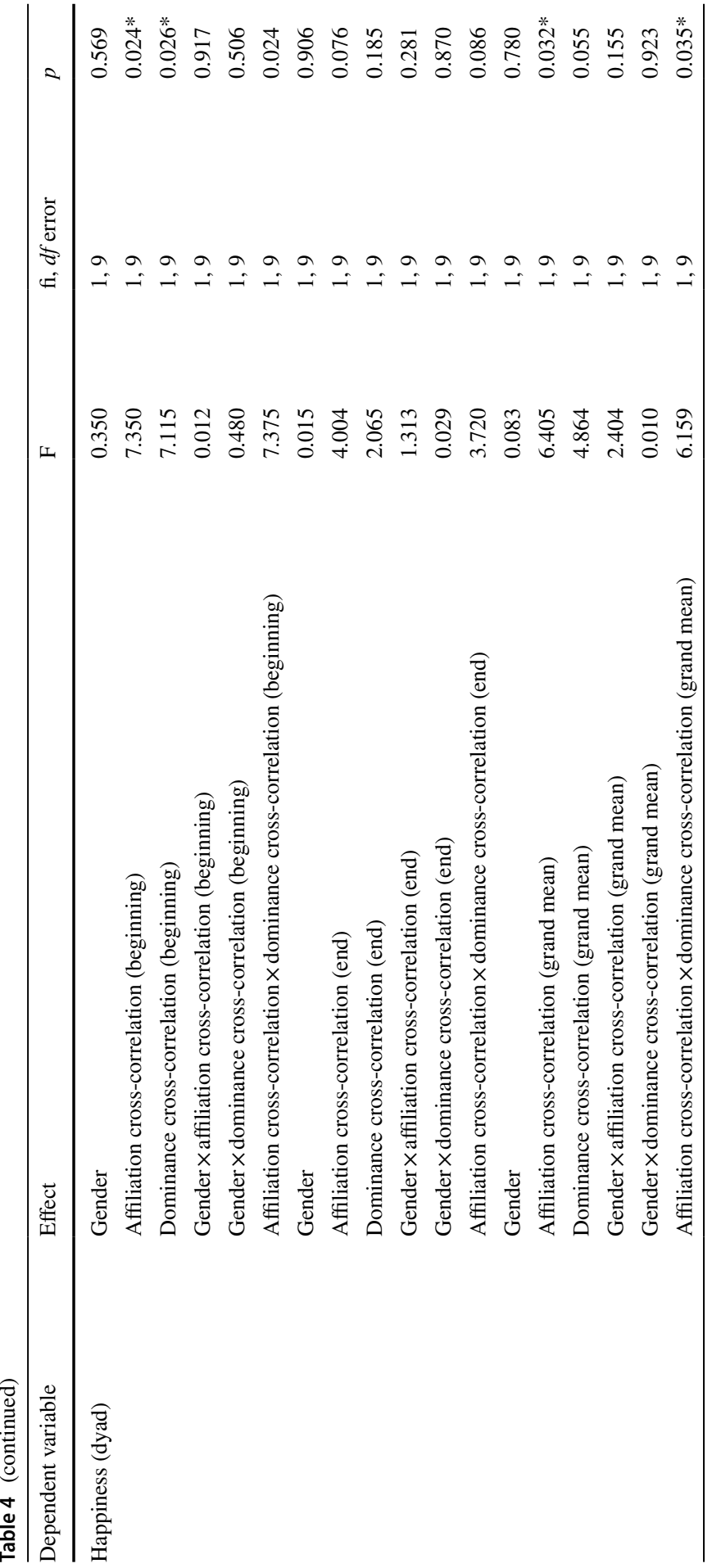




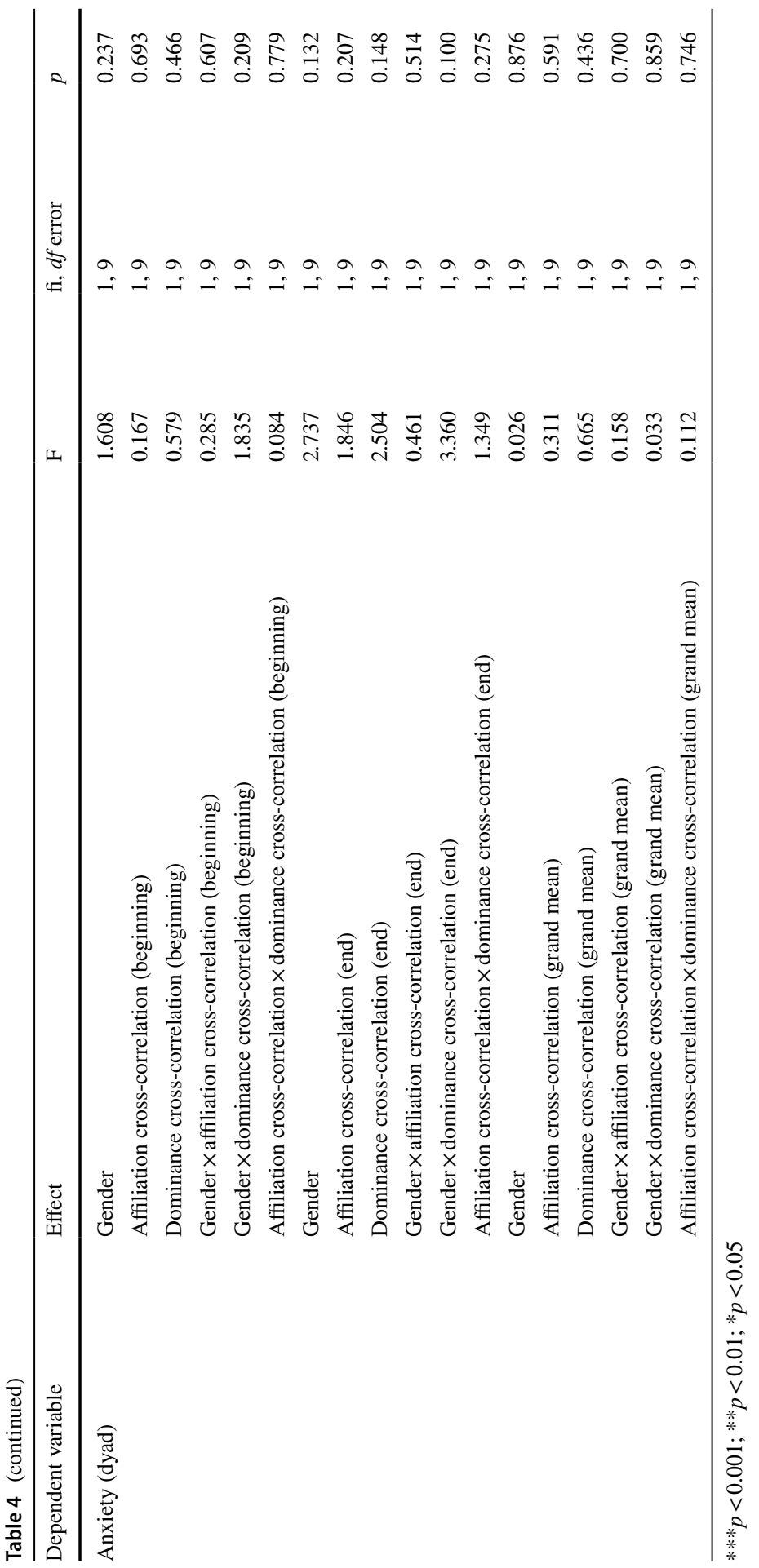




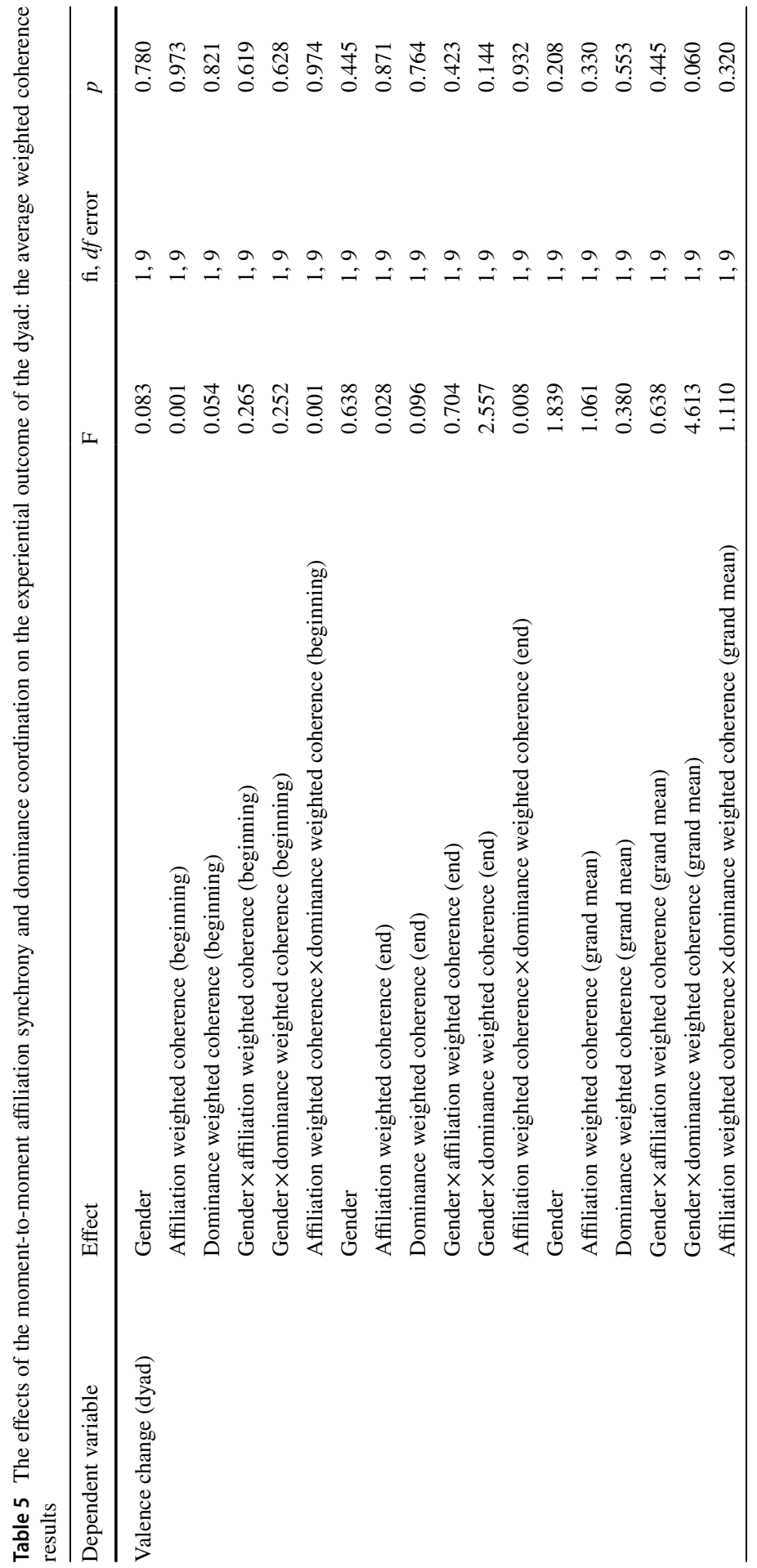




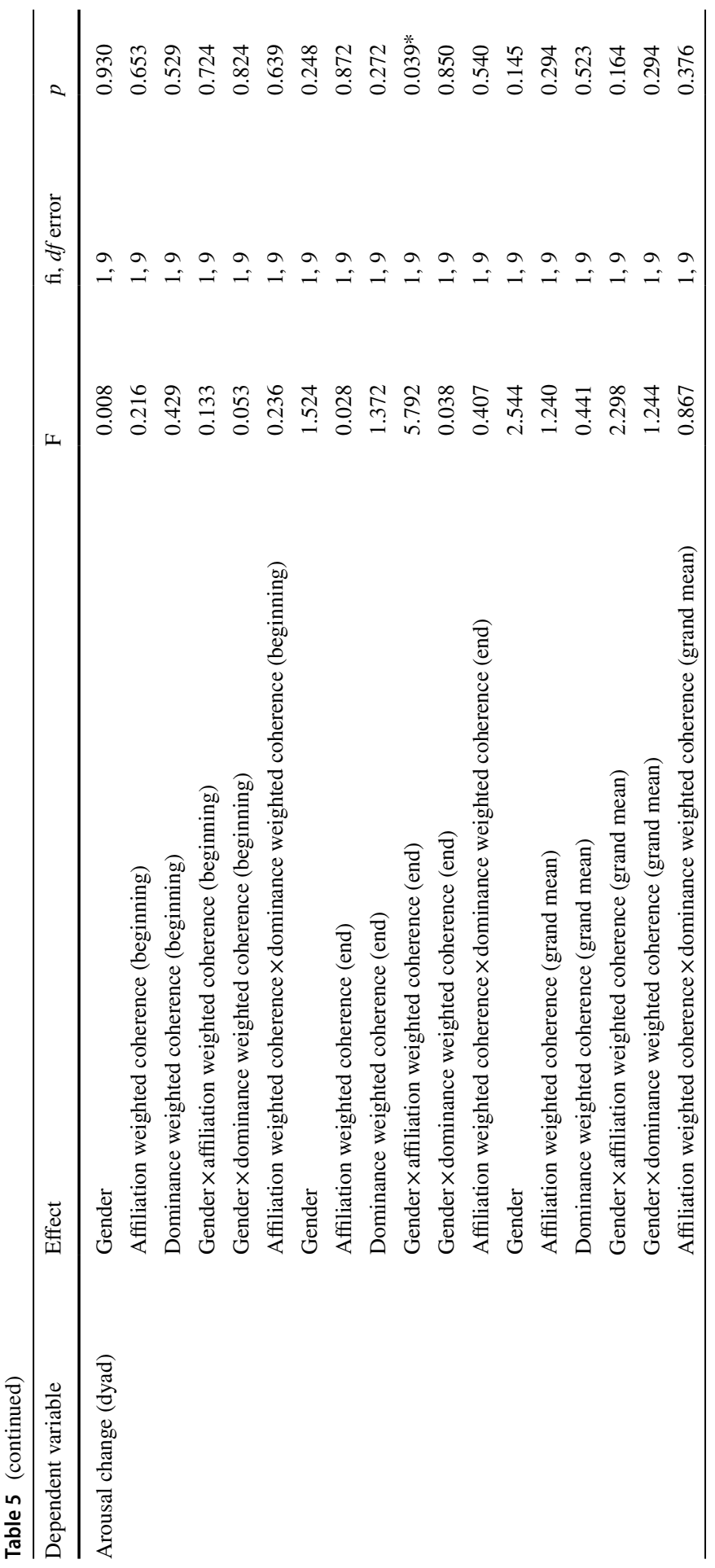




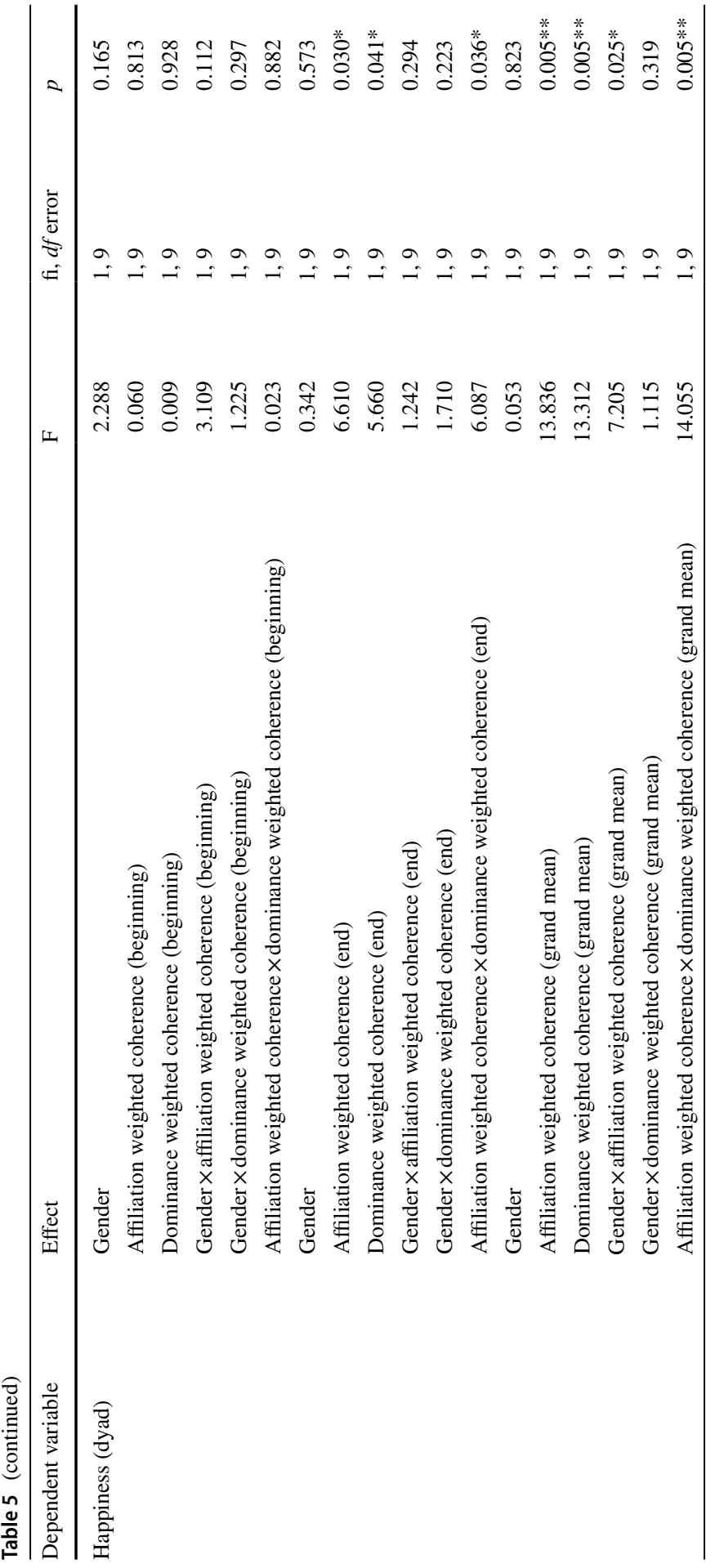




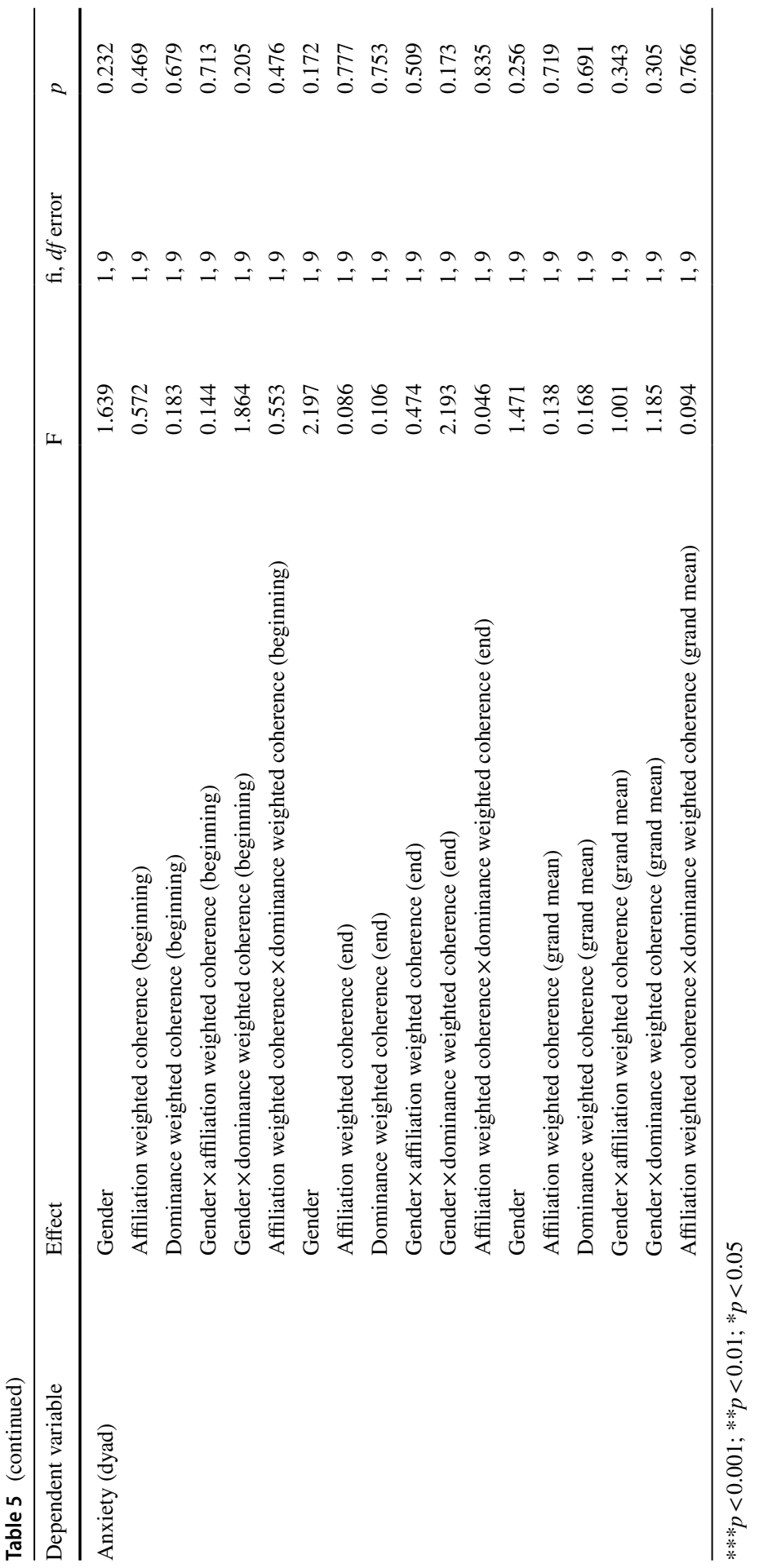




\section{References}

1. Anderson, K. J., \& Leaper, C. (1998). Meta-analyses of gender effects on conversational interruption: Who, what, when, where, and how. Sex Roles, 39, 225-252. https://doi.org/10.1023/A:10188 02521676.

2. Aries, E. (1996). Men and women in interaction: Reconsidering the differences. New York: Oxford University Press.

3. Bakan, D. (1966). The duality of human existence: An essay on psychology and religion. Oxford, UK: Rand McNally.

4. Basow, S. A., \& Rubenfeld, K. (2003). "Troubles talk": Effects of gender and gender typing. Sex Roles, 48, 183-187. https://doi.org/10.1023/A:1022411623948.

5. Bradley, M. M., \& Lang, P. J. (1994). Measuring emotion: The self-assessment manikin and the semantic differential. Journal of Behavior Therapy and Experimental Psychiatry, 25, 49-59. https:// doi.org/10.1016/0005-7916(94)90063-9.

6. Brainard, D. H. (1997). The psychophysics toolbox. Spatial Vision, 10, 433-436. http://color.psych .ucsb.edu/psychtoolbox.

7. Briton, N. J., \& Hall, J. A. (1995). Beliefs about female and male nonverbal communication. Sex Roles, 32, 79-90. https://doi.org/10.1007/BF01544758.

8. Brody, L. R. (1999). Gender, emotion, and the family. Cambridge, MA: Harvard Univeristy Press.

9. Brody, L. R. (2000). The socialization of gender differences in emotional expression: Display rules, infant temperament, and differentiation. In A. H. Fischer (Ed.), Gender and emotion: Social psychological perspectives (pp. 24-47). Cambridge, UK: Cambridge University Press.

10. Bugental, D. E., Love, L. R., \& Gianetto, R. M. (1971). Perfidious feminine faces. Journal of Personality and Social Psychology, 17, 314-318. https://doi.org/10.1037/h0030586.

11. Carson, R. C. (1969). Interaction concepts of personality. Chicago, IL: Aldine.

12. Chaplin, T. M., \& Aldao, A. (2013). Gender differences in emotion expression in children: A metaanalytic review. Psychological Bulletin, 139, 735-765. https://doi.org/10.1037/a0030737.

13. Chovil, N. (1991). -1992). Discourse-oriented facial displays in conversation. Research on Language and Social Interaction, 25, 163-194. https://doi.org/10.1080/08351819109389361.

14. Coates, J. (1994). No gap, lots of overlap: Turn-taking patterns in the talk of women friends. In D. Graddol, J. Maybin, \& B. Stierer (Eds.), Researching language and and literacy in social context (pp. 177-192). Clevedon: Multilingual Matters.

15. Coleman, T. (2000). Using video-recorded consultations for research in primary care: advantages and limitations. Family Practice, 17(5), 422-427. https://doi.org/10.1093/fampra/17.5.422.

16. Collins, R. (2004). Interaction ritual chains. Princeton, NJ: Princeton University Press.

17. Cronbach, L. J. (1951). Coefficient alpha and the internal structure of tests. Psychometrika, 16(3), 297-334. https://doi.org/10.1007/BF02310555.

18. Eagly, A. H. (1987). Sex differences in social behavior: A social-role interpretation. Hillsdale, NJ: Erlbaum.

19. Enfield, N. J. (2011). Sources of asymmetry in human interaction: Enchrony, status, knowledge and agency. In T. Stivers, L. Mondada, \& J. Steensig (Eds.), The morality of knowledge in conversation (pp. 285-312). Cambridge: Cambridge University Press.

20. Giles, H. (2008). Communication accommodation theory. In L. A. Baxter \& D. O. Braithewaite (Eds.), Engaging theories in interpersonal communication: Multiple perspectives (pp. 161-173). Thousand Oaks, CA: Sage Publications Inc.

21. Goffman, E. (1967). Interaction ritual: Essays on face-to-face behavior. New York, NY: Pantheon.

22. Gurtman, M. B. (1997). The interpersonal circumplex. http://www.uwp.edu/academic/psychology/ faculty/netcirc.htm.

23. Gurtman, M. B. (2001). Interpersonal complementarity: Integrating interpersonal measurement with interpersonal models. Journal of Counseling Psychology, 48, 97-110. https://doi. org/10.1037/0022-0167.48.1.97.

24. Hall, J. A. (1984). Nonverbal sex differences: Communication accuracy and expressive style. Baltimore, MD: Johns Hopkins University Press.

25. Hall, J. A. (1998). How big are nonverbal sex differences? The case of smiling and sensitivity to nonverbal cues. In D. Canary \& K. Dindia (Eds.), Sex differences and similarities in communication (pp. 155-178). Mahwah, NJ: Erlbaum. 
26. Hall, J. A., \& Halberstadt, A. G. (1986). Smiling and gazing. In J. S. Hyde \& M. C. Linn (Eds.), The psychology of gender: Advances through meta-analysis (pp. 136-158). Baltimore, MD: John Hopkins University Press.

27. Hatfield, E., Cacioppo, J., \& Rapson, R. L. (1994). Emotional contagion. New York: Cambridge University Press.

28. Helweg-Larsen, M., Cunningham, S., Carrico, A., \& Pergram, A. (2004). To nod or not to nod: An observational study of nonverbal communication and status in female and male college students. Psychology of Women Quarterly, 28, 358-361. https://doi.org/10.1111/j.1471-6402.2004.00152.x.

29. Hochschild, A. (1979). Emotion work, feeling rules, and social structure. American Journal of Sociology, 85, 551-575. http://www.jstor.org/stable/2778583.

30. Hochschild, Arlie. (1983). The managed heart: Commercialization of human feeling. Berkeley: University of California Press.

31. Jaffe, J., Beebe, B., Feldstein, S., Crown, C. L., \& Jasnow, M. (2001). Rhythms of dialogue in infancy: Coordinated timing in development. Monographs of the Society for Research in Child Development, 66(2), 1-132.

32. Kiesler, D. J. (1983). The 1982 Interpersonal Circle: A taxonomy for complementarity in human transactions. Psychological Review, 90, 185-214. https://doi.org/10.1037/0033-295X.90.3.185.

33. Kiesler, D. J. (1996). Contemporary interpersonal theory and research: Personality, psychopathology, and psychotherapy. New York, NY: Wiley.

34. Kleiner, M., Brainard, D., \& Pelli, D. (2007). "What's new in Psychtoolbox-3?" Perception, 36, ECVP Abstract Supplement. http://psychtoolbox.org/credits.

35. LaFrance, M., Hecht, M. A., \& Levy Paluck, E. (2003). The contingent smile: A metaanalysis of sex differences in smiling. Psychological Bulletin, 129, 305-334. https://doi. org/10.1037/0033-2909.129.2.305.

36. Lakoff, R. T. (1975). Language and woman's place. New York: Harper \& Row.

37. Leaper, C. (1991). Influence and involvement in children's discourse: Age, gender, and partner effects. Child Development, 62, 797-811. https://doi.org/10.1111/j.1467-8624.1991.tb01570.x.

38. Leaper, C., \& Ayres, M. M. (2007). A meta-analytic review of gender variations in adults' language use: Talkativeness, affiliative speech, and assertive speech. Personality and Social Psychology Review, 11, 328-363. https://doi.org/10.1177/1088868307302221.

39. Leary, T. (1957). Interpersonal diagnosis of personality. New York: Ronald Press.

40. Lizdek, I., Sadler, P., Woody, E., Ethier, N., \& Malet, G. (2012). Capturing the stream of behavior: A computer-joystick method for coding interpersonal behavior continuously over time. Social Science Computer Review, 30, 513-521. https://doi.org/10.1177/0894439312436487.

41. Lomax, H., \& Casey, N. (1998). Recording social life: Reflexivity and video methodology. Sociological Research Online, 3(2), 1-26. https://doi.org/10.5153/sro.1372.

42. Maltz, D. N., \& Borker, R. (1982). A cultural approach to male-female miscommunication. In J. J. Gumpertz (Ed.), Language and social identity. Cambridge: Cambridge University Press.

43. Manson, J. H., Bryant, G. A., Gervais, M. M., \& Kline, M. A. (2013). Convergence of speech rate in conversation predicts cooperation. Evolution and Human Behavior, 34, 419-426. https://doi. org/10.1016/j.evolhumbehav.2013.08.001.

44. Markey, P. M., Funder, D. C., \& Ozer, D. J. (2003). Complementarity of interpersonal behaviors in dyadic interactions. Personality and Social Psychology Bulletin, 29(9), 1082-1090. https://doi. org/10.1177/0146167203253474.

45. Mason, E. S. (1994). Gender differences in job satisfaction. The Journal of Social Psychology, 135, 143-151. https://doi.org/10.1080/00224545.1995.9711417.

46. Maynard, D., \& Zimmerman, D. (1984). Topical talk, ritual and the social organization of relationships. Social Psychology Quarterly, 47(4), 301-316.

47. McClure, E. B. (2000). A meta-analytic review of sex differences in facial expression processing and their development in infants, children, and adolescents. Psychological Bulletin, 126, 424-453. https:// doi.org/10.1037/0033-2909.126.3.424.

48. Moskowitz, D. S. (1994). Cross-situational generality and the interpersonal circumplex. Journal of Personality and Social Psychology, 66(5), 921. https://doi.org/10.1037/0022-3514.66.5.921.

49. Mulac, A., Wiemann, J., Widenmann, S., \& Gibson, T. (1988). Male/female language differences and effects in same-sex and mixed-sex dyads: The gender-linked language effect. Communication Monographs, 55, 315-335. https://doi.org/10.1080/03637758809376175. 
50. Myllyniemi, R. (1997). The interpersonal circle and the emotional undercurrents of human sociability. In R. Plutchik \& H. R. Conte (Eds.), Circumplex models of personality and emotions (pp. 271-295). Washington, DC: APA.

51. Natale, M. (1975). Convergence of mean vocal intensity in dyadic communication as a function of social desirability. Journal of Personality and Social Psychology, 32, 790-804. https://doi. org/10.1037/0022-3514.32.5.790.

52. Pardo, J. S. (2006). On phonetic convergence during conversational interaction. The Journal of the Acoustical Society of America, 119(4), 2382-2393. https://doi.org/10.1121/1.2178720.

53. Pearson, J. C. (1985). Gender and communication. Dubuque, IA: William C. Brown.

54. Pelli, D. G. (1997). The VideoToolbox software for visual psychophysics: Transforming numbers into movies. Spatial Vision, 10(4), 437-442. https://doi.org/10.1163/156856897X00366.

55. Peräkylä, A., Henttonen, P., Voutilainen, L., Kahri, M., Stevanovic, M., Sams, M., et al. (2015). Sharing the emotional load recipient affiliation calms down the storyteller. Social Psychology Quarterly, 78, 301-323. https://doi.org/10.1177/0190272515611054.

56. Porges, S. W., Bohrer, R. E., Cheung, M. N., Drasgow, F., McCabe, P. M., \& Keren, G. (1980). New time-series statistic for detecting rhythmic co-occurrence in the frequency domain: The weighted coherence and its application to psychophysiological research. Psychological Bulletin, 88(3), 580-587. https ://doi.org/10.1037/0033-2909.88.3.580.

57. Pringle, M., \& Stewart-Evans, C. (1990). Does awareness of being video recorded affect doctors' consultation behaviour? British Journal of General Practice, 40(340), 455-458.

58. Quina, K., Wingard, J. A., \& Bates, H. G. (1987). Language style and gender stereotypes in person perception. Psychology of Women Quarterly, 11, 111-122. https://doi.org/10.1111/j.1471-6402.1987.tb007 78.x.

59. Rafaeli, E., Rogers, G. M., \& Revelle, W. (2007). Affective synchrony: Individual differences in mixed emotions. Personality and Social Psychology Bulletin, 33, 915-932. https://doi.org/10.1177/01461 67207301009.

60. Rosenthal, R., Hall, J. A., DiMatteo, M. R., Roger, P. L., \& Archer, D. (1979). Sensitivity to nonverbal communication: The PONS test. Baltimore, MD: The Johns Hopkins University Press.

61. Sadler, P., Ethier, N., Gunn, G. R., Duong, D., \& Woody, E. (2009). Are we on the same wavelength? Complementarity as shared cyclical patterns within an interaction. Journal of Personality and Social Psychology, 97, 1005-1020. https://doi.org/10.1037/a0016232.

62. Sadler, P., Ethier, N., \& Woody, E. (2011). Interpersonal complementarity. In L. M. Horowitz \& S. N. Strack (Eds.), Handbook of interpersonal psychology: Theory, research, assessment, and therapeutic interventions (pp. 124-142). New York, NY: Wiley.

63. Schaefer, E. S. (1961). Converging conceptual models for maternal behavior and child behavior. In J. C. Glidwell (Ed.), Parental attitudes and child behavior (pp. 124-146). Springfield, IL: Charles C. Thomas.

64. Smith, J. L., \& Ruiz, J. M. (2007). Interpersonal orientation in context: Correlates and effects of interpersonal complementarity on subjective and cardiovascular experiences. Journal of Personality, 75, 679-708. https://doi.org/10.1111/j.1467-6494.2007.00453.x.

65. Spector, P. E. (1994). Using self-report questionnaires in OB research: A comment on the use of a controversial method. Journal of Organizational Behavior, 15, 385-392. https://doi.org/10.1002/job.40301 50503.

66. Statham, A. (1987). The gender model revisited: Differences in the management styles of men and women. Sex Roles, 16, 409-429. https://doi.org/10.1007/BF00289552.

67. Stevanovic, M., Henttonen, P., Koski, S., Kahri, M., Voutilainen, L., Koskinen, E., Nieminen-von Wendt, T., Tani, P., \& Peräkylä, A. (2017). On the Asperger experience of interaction: Interpersonal dynamics in dyadic conversations. Journal of Autism. https://doi.org/10.7243/2054-992X-4-2.

68. Sullivan, H. S. (1953). The interpersonal theory of psychiatry. New York: Norton.

69. Svennevig, J. (2000). Getting acquainted in conversation: A study of initial interactions. Amsterdam: John Benjamins Publishing.

70. Svennevig, J. (2014). Direct and indirect self-presentation in first conversations. Journal of Language and Social Psychology, 33(3), 302-327. https://doi.org/10.1177/0261927X13512307.

71. Tannen, D. (1984). Conversational style: Analyzing talk among friends. Norwood, NJ: Ablex.

72. Tannen, D. (1990). You just don't understand: Women and men in conversation. New York: Ballantine.

73. Tannen, D. (2007). Talking voices. Repetition, dialogue, and imagery in conversational discourse (2nd ed.). Cambridge: Cambridge University Press. 
74. Thompson, E. R. (2007). Development and validation of an internationally reliable short-form of the positive and negative affect schedule (PANAS). Journal of Cross-Cultural Psychology, 38(2), 227-242. https://doi.org/10.1177/0022022106297301.

75. Thorne, B., \& Henley, N. (1975). Difference and dominance: An overview of language, gender, and society. In B. Thorne \& N. Henley (Eds.), Language and sex: Difference and dominance (pp. 5-42). Rowley, MA: Newbury House Publishers.

76. Tiedens, L. Z., \& Fragale, A. R. (2003). Power moves: Complementarity in submissive and dominant nonverbal behavior. Journal of Personality and Social Psychology, 84, 558-568. https://doi. org/10.1037/0022-3514.84.3.558.

77. Tuncer, S. (2016). The effects of video recording on office workers' conduct, and the validity of video data for the study of naturally-occurring interactions. Forum: Qualitative Social Research, 17(3), 7.

78. Vogel, D. L., Wester, S. R., Heesacker, M., \& Madon, S. (2003). Confirming gender stereotypes: A social role perspective. Sex Roles, 48, 519-528. https://doi.org/10.1023/A:1023575212526.

79. Watson, D., \& Clark, L. A. (1994). The PANAS-X: Manual for the positive and negative affect schedule-Expanded form. Iowa City: University of Iowa.

80. Watson, D., Clark, L. A., \& Tellegen, A. (1988). Development and validation of brief measures of positive and negative affect: The PANAS scales. Journal of Personality and Social Psychology, 54, 10631070. https://doi.org/10.1037/0022-3514.54.6.1063.

81. Widiger, T. A. (2010). Personality, interpersonal circumplex, and DSM-5: A commentary on five studies. Journal of Personality Assessment, 92, 528-532. https://doi.org/10.1080/00223891.2010.513707.

82. Wiggins, J. S. (1982). Circumplex models of interpersonal behavior in clinical psychology. In P. C. Kendall \& J. N. Butcher (Eds.), Handbook of research methods in clinical psychology (pp. 183-221). New York: Wiley.

83. Wiggins, J. S. (2003). The interpersonal paradigm. In J. S. Wiggins (Ed.), Paradigms of personality assessment (pp. 63-92). New York, NY: Guilford.

84. Wilkinson, S., \& Kitzinger, C. (2008). Using conversation analysis in feminist and critical research. Social and Personality Psychology Compass, 2, 555-573. https://doi.org/10.111 1/j.1751-9004.2007.00049.x.

85. Wood, J. T. (1996). Gendered lives: Communication, gender and culture (2nd ed.). Belmont, CA: Wadsworth.

86. Yaughn, E., \& Nowicki, S. (1999). Close relationships and complementary interpersonal styles among men and women. Journal of Social Psychology, 139, 473-478. https://doi.org/10.1080/00224 549909598406. 